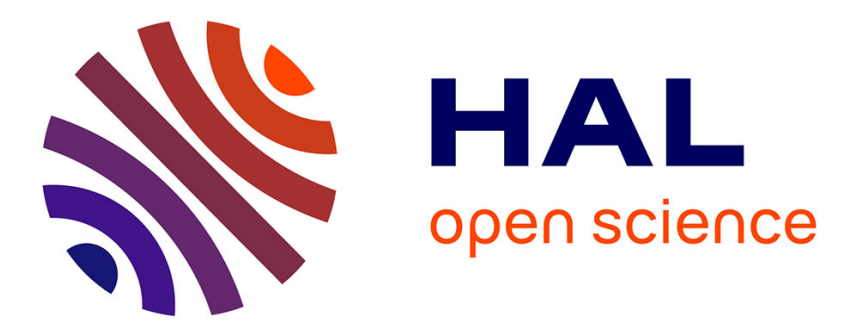

\title{
Deciphering the desiccation trend of the South Asian monsoon hydroclimate in a warming world
}

R. Krishnan, T. P. Sabin, R. Vellore, Milind Mujumdar, J. Sanjay, B. N. Goswami, Frédéric Hourdin, Jean-Louis Dufresne, Pascal Terray

\section{- To cite this version:}

R. Krishnan, T. P. Sabin, R. Vellore, Milind Mujumdar, J. Sanjay, et al.. Deciphering the desiccation trend of the South Asian monsoon hydroclimate in a warming world. Climate Dynamics, 2016, 47 (3), pp.1007-1027. 10.1007/s00382-015-2886-5 . hal-01322856

\section{HAL Id: hal-01322856 https://hal.science/hal-01322856}

Submitted on 27 May 2016

HAL is a multi-disciplinary open access archive for the deposit and dissemination of scientific research documents, whether they are published or not. The documents may come from teaching and research institutions in France or abroad, or from public or private research centers.
L'archive ouverte pluridisciplinaire HAL, est destinée au dépôt et à la diffusion de documents scientifiques de niveau recherche, publiés ou non, émanant des établissements d'enseignement et de recherche français ou étrangers, des laboratoires publics ou privés. 


\title{
Deciphering the desiccation trend of the South Asian monsoon hydroclimate in a warming world
}

\author{
R. Krishnan ${ }^{1 *}$, T.P. Sabin ${ }^{1}$, R. Vellore ${ }^{1}$, M. Mujumdar ${ }^{1}$, J. Sanjay ${ }^{1}$, B. N. Goswami ${ }^{1,2}$, F. \\ Hourdin $^{3}$, J-L. Dufresne ${ }^{3}$, P. Terray ${ }^{4,5}$
}

${ }^{1}$ Centre for Climate Change Research (CCCR), Indian Institute of Tropical Meteorology (IITM), 14 Pune, India.

$15 \quad{ }^{2}$ Indian Institute of Science, Education and Research (IISER), Pune, India.

16 32Laboratoire Meteorologie Dynamique, (LMD/IPSL), Centr National de la Recherche 17 Scientifique (CNRS)/ Université Pierre et Marie Curie (UPMC)/ENS/Ecole Polytechnique, Paris, 18 France.

${ }^{4}$ Sorbonne Universités (UPMC, Univ Paris 06)-CNRS-IRD-MNHN, LOCEAN Laboratory, 4 place Jussieu, F-75005 Paris, France

${ }^{5}$ Indo-French Cell for Water Sciences, IISc-NIO-IITM-IRD Joint International Laboratory, IITM, Pune, India.

*Correspondence should be addressed to R.K (krish@tropmet.res.in)

Tel: +912025904301

Fax: +912025865142 


\section{Abstract}

Rising propensity of precipitation extremes and concomitant decline of summer-monsoon rains are amongst the most distinctive hydroclimatic signals that have emerged over South Asia since 1950s. A clear understanding of the underlying causes driving these monsoon hydroclimatic signals has remained elusive. Using a state-of-the-art global climate model with high-resolution zooming over South Asia, we demonstrate that a juxtaposition of regional land-use changes, anthropogenic-aerosol forcing and the rapid warming signal of the equatorial Indian Ocean is crucial to produce the observed monsoon weakening in recent decades. Our findings also show that this monsoonal weakening significantly enhances occurrence of localized intense precipitation events, as compared to the global-warming response. A $21^{\text {st }}$ century climate projection using the same high-resolution model indicates persistent decrease of monsoonal rains and prolongation of soil drying. Critical value-additions from this study include (a) realistic simulation of the mean and long-term historical trends in the Indian monsoon rainfall (b) robust attributions of changes in moderate and heavy precipitation events over Central India (c) a $21^{\text {st }}$ century projection of drying trend of the South Asian monsoon. The present findings have profound bearing on the regional water-security, which is already under severe hydrologicalstress.

9 


\section{Introduction}

Countries in South-Asia are endowed with bountiful summer-monsoon (June-September) precipitation which is the principal water-supply source for sustaining agricultural operations, power-generation, ecosystems and livelihoods of over 1.6 billion inhabitants and pivotal for the regional hydrological cycle (Bookhagen and Burbank 2010; Hasson et al. 2013). Whilst the inter-annual variability of the South-Asian Monsoon (SAM, also called 'Indian monsoon') rainfall is tightly linked to El Nino-Southern Oscillation (Mishra et al. 2012), several studies have reported significant declining trends in the SAM rainfall (e.g. Chung and Ramanathan 2005; Bollasina et al. 2011; Krishnan et al. 2013; Singh et al. 2014 and others) and associated increase of aridity in recent decades (Kumar et al. 2013). The 144-year (1871-2014) time-series of all-India summer monsoon rainfall (AISMR) reveals 10 occurrences of monsoon-droughts during the first half (1871-1943), while the second half (1944-2014) witnessed 15 monsoondroughts $^{1}$ - i.e., a clear increase of drought incidence during the second half relative to the first. The summer monsoon precipitation averaged over the Indian region $\left(70-90^{\circ} \mathrm{E}-10-28^{\circ} \mathrm{N}\right)$ declined by $\sim 7 \%$ during 1951-2005, significantly over the west coast and Indo-Gangetic plains of north and east-central India as evidenced from observed rainfall datasets (e.g. Guhathakurtha and Rajeevan 2008; Rajendran et al. 2012; Krishnan et al. 2013; Table 1). The decreasing trend of SAM rainfall is corroborated by a significant weakening of monsoon low-level southwesterly winds, the upper-tropospheric tropical easterlies from the outflow aloft, the large-scale monsoon meridional overturning circulations (Rao et al. 2004; Joseph and Simon 2005; Sathiyamoorthi

${ }^{1}$ There were 25 cases of monsoon droughts during 1871-2014 corresponding to the years 1873, 1877, 1899, 1901, 1904, 1905, 1911, 1918, 1920, 1941, 1951, 1965, 1966, 1968, 1972, 1974, 1979, 1982, 1985, 1986, 1987, 2002, 2004, 2009 and 2014. A monsoon-drought over India is defined when the AISMR deficiency exceeds one standarddeviation of long-term climatological mean. The June to September climatological seasonal total of AISMR is 848 $\mathrm{mm}$ and the standard-deviation is about $10 \%$ of the mean (see http://www.tropmet.res.in). 
2005; Abish et al. 2013; Fan et al. 2010; Krishnan et al. 2013) and a significant increase in the duration and frequency of 'monsoon-breaks' (dry spells) over India since 1970s (e.g. Ramesh Kumar et al. 2009; Turner and Hannachi 2010). The weakening of SAM circulation is also borne out from the declining frequency of the Bay of Bengal (BOB) monsoon depressions - the primary rain-producing synoptic-scale monsoon disturbances (e.g. Rajeevan et al. 2000; Krishnamurti et al. 2013; Singh et al. 2014). Concomitant with the declining monsoonal rains, the Indian region additionally experienced a substantial rise in the frequency of daily precipitation extremes in the post-1950s (Goswami et al. 2006; Rajeevan et al. 2008). Even as these regional hydroclimatic changes tend to exacerbate the already diminishing water levels, the underlying reasons are still unclear (Rodell et al. 2009).

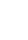

Increase of atmospheric moisture content in response to global warming is expected to enhance precipitation over broader regions of Asia and other monsoonal areas (e.g. Kitoh et al. 1997; Meehl and Arblaster 2003; May 2011; Wang et al. 2014). This is consistent with the observed increasing trend in the intensity of "global monsoon" precipitation during the past three decades, which has been attributed to enhanced moisture convergence and surface evaporation due to increasing surface temperature (Hsu et al. 2012; Lau et al. 2013; Kitoh et al. 2013; Wang et al. 2014). However, the Coupled-Model-Intercomparison-Project (CMIP) models show wide inter-model spread in the simulated precipitation changes over South Asia, so that assessments of regional hydroclimatic response to climate change have remained ambiguous (e.g. Kripalani et al. 2007; Annamalai et al. 2007; Turner and Slingo 2009; Sabade et al. 2011; Fan et al. 2010; Hasson et al. 2013; Saha et al. 2014). While most models suggest a greater likelihood of enhanced monsoon precipitation due to global warming, they indicate a likely weakening of 
large-scale monsoon and tropical circulation (e.g. Kitoh et al. 1997; Douville, 2000; Ueda et al. 2006; Cherchi et al. 2011; Rajendran et al. 2012; Krishnan et al. 2013).

Greenhouse-gas (GHG) and anthropogenic-aerosol forcing are generally regarded to exert opposing influences on the SAM, with the former being conducive for precipitation enhancement (e.g. Bollasina et al. 2011). Recent studies have attributed the observed declining trend of SAM to anthropogenic-aerosol forcing (e.g. Ramanathan et al. 2005, Chung and Ramanathan 2006, Bollasina et al. 2011). The impact of anthropogenic aerosols on surface cooling over the Indian region is also seen in surface temperature observations, particularly during the winter and pre-monsoon seasons (Krishnan and Ramanathan, 2002). Krishnamurti et al. (2013) suggested that rapid increase of anthropogenic aerosol emissions over China and South Asia in recent decades have enhanced the potential for disrupting organized convection in the BOB monsoon depressions through aerosol indirect effects. Owing to the strong internal variability of the Asian monsoon, aerosol impacts on monsoon precipitation are detectable mostly on broader continental scales (e.g. South and Southeast Asia) and not as much on smaller spatial scales (Salzmann et al. 2014). While the direct effects of aerosols on radiation and climate are relatively better understood, there are considerable uncertainties concerning aerosol indirect effects on tropical clouds and monsoon precipitation systems (e.g. Stevens and Feingold 2009; Gautam et al. 2009; Turner and Annamalai 2012). A comparison of CMIP Phase-5 (CMIP5) simulations between models with and without aerosol indirect effects showed large differences in the SAM precipitation response during the second half of the $20^{\text {th }}$ century (Guo et al. 2015). Also the CMIP5 models show poor skills in simulating the recent declining trend of SAM rainfall, with large ambiguities in future projections of monsoon rainfall (e.g. Chaturvedi et al. 2013; Saha et al. 2014; Sharmila et al. 2014). Therefore, reliable attribution of the recent decline of 
SAM rainfall yet remains a challenging problem given the large decadal-scale natural variations of the monsoon system (Sinha et al. 2015).

Besides increasing GHGs and anthropogenic-aerosols, the South-Asian region also underwent prominent changes in other forcing elements. Historical analysis of land-use change in South and Southeast-Asia indicates that large-scale deforestation, agricultural expansion and wetland clearance led to massive decline $(\sim 47 \%)$ of forests/woodlands in the last century while agricultural land-area nearly doubled as that of 1880 (Flint and Richards 1991; Ramankutty et al. 2006). Another distinct regional signal is the rapid warming of equatorial Indian Ocean SST (IOSST) by $0.5^{\circ}-1^{\circ} \mathrm{C}$ during the last few decades (Mishra et al. 2012; Alory and Meyers 2009; Swapna et al. 2013). The acceleration of the equatorial IOSST trend, which is in excess of the global-warming signal, involves changes in the Indian Ocean circulation in response to weakening of the summer monsoon cross-equatorial flow in the recent decades (Swapna et al. 2013). The rapid IOSST warming also favors enhancement of near-equatorial convection and warming of the equatorial troposphere (Krishnan et al. 2006; Abish et al. 2013).

The objective of this study is to investigate the basis for the recent SAM changes and draw insights into the mechanisms involved. For this purpose, we perform a suite of long-term simulations in this study by employing a state-of-the-art variable resolution global climate model (LMDZ4), developed at the Laboratoire de Météorologie Dynamique, France, having highresolution telescopic zooming (horizontal grid size $\sim 35 \mathrm{~km}$ ) over South-Asia. The use of highresolution overcomes the inadequacies and stringent limitations of coarse-resolution models in representing surface topography and regional processes - particularly those involving land-use change and aerosol-forcing. This is important from the viewpoint of regional-scale feedbacks 
146 (eg., planetary-albedo) on the long-term behavior and stability of the Indian monsoon (Lenton et 147 al. 2008). Unlike limited-area models, another advantage of using a global variable-resolution model is that it excludes imposition of time-dependent lateral boundary-conditions of 3D atmospheric fields from global simulations. Furthermore, high-resolution is essential for understanding changes in intense precipitation events (rain rate $>100 \mathrm{~mm} \mathrm{day}^{-1}$ ) over the SAM region, which are poorly represented in the CMIP models. A recent study by Sabin et al. (2013) showed that the high-resolution LMDZ4 general circulation model (GCM) produces realistic simulations of the mean SAM precipitation, organized moist convective processes and monsoon synoptic disturbances. Datasets and model description are discussed in the following section.

\section{Datasets and Model}

\subsection{Datasets}

The observed precipitation datasets used for the analysis include (a) The India Meteorological Department (IMD) high-resolution gridded $\left(0.25^{\circ} \times 0.25^{\circ}\right)$ daily rainfall data for the period 19012010 over the Indian region (Pai et.al., 2014) (b) The Asian Precipitation Highly Resolved Observational Data Integration Towards Evaluation of Water Resources (APHRODITE) gridded $\left(0.5^{\circ} \times 0.5^{\circ}\right)$ rainfall over the Monsoon Asia land region $\left(60^{\circ} \mathrm{E}-150^{\circ} \mathrm{E}, 15^{\circ} \mathrm{S}-55^{\circ} \mathrm{N}\right)$ for the period 1951-2007 (Yatagai et al. 2012) and (c) The Global Precipitation Climatology Project (GPCP Version 2) gridded $\left(2.5^{\circ} \times 2.5^{\circ}\right)$ rainfall dataset for the period 1979-2009 (Adler et al. 2003). We also use the observed gridded $\left(0.5^{\circ} \times 0.5^{\circ}\right)$ monthly surface temperature dataset during 1901-2010 from Climate Research Unit (CRU) (http://badc.nerc.ac.uk/view/badc.nerc.ac.uk); monthly sea surface temperature (SST) and sea level pressure (SLP) during 1886-2005 based on the HadISST (Rayner et al. 2003) and HadSLP (Allan and Ansell 2006) datasets, respectively. 
Additionally, we used monthly mean atmospheric winds from the National Center for Environmental Prediction (NCEP) Reanalysis for the period 1950-2005 (Kistler et al. 2001).

\subsection{Brief description of LMDZ4 GCM}

The LMDZ4 GCM is the atmospheric component of the Institut Pierre Simon Laplace (IPSL) coupled model (Hourdin et al. 2006; Dufresne et al. 2013) and has been used to produce climate change simulations for the Intergovernmental Panel for Climate Change (IPCC). It includes a comprehensive treatment of atmospheric physical processes and land-surface components and incorporates GHG-forcing and explicit representation of aerosol-radiation-cloud interactions. The dynamical part of LMDZ4 is based on a finite-difference formulation of the primitive equations of meteorology discretized on a sphere with stretchable grid ( $Z$ in LMDZ stands for zoom) and uses the hybrid $\sigma-$ p coordinate with 19 vertical layers (Sadourny and Laval 1984; Hourdin et al. 2006). The energy and water cycles of soil and vegetation, terrestrial carbon cycle, vegetation composition are simulated by a land-surface component known as Organizing Carbon and Hydrology in Dynamic EcosystEms (ORCHIDEE) (Krinner et al. 2005). Land surface is described as a mosaic of twelve plant functional types and bare soil. We designed a specific gridconfiguration by including high-resolution telescopic zooming $(\sim 35 \mathrm{~km}$ in longitude and latitude) centered at $15^{\circ} \mathrm{N}, 80^{\circ} \mathrm{E}$ to simulate finer details of the SAM (Sabin et al. 2013).

\subsection{IPSL-CM5 Coupled Model}

The IPSL-CM5 coupled model couples the LMDZ atmosphere-land surface model to an oceansea ice model (Dufresne et al. 2013). The ocean GCM (NEMOv3.2) ensures better representation of bottom bathymetry, stream flow and friction at the bottom of the ocean, improved mixed-layer dynamics, double diffusion, tracer diffusion and several key ocean processes including 
prognostic interaction between incoming shortwave radiation into the ocean and the phytoplankton. The IPSL-CM5 coupled model simulations have been generated for two atmospheric grids. The low resolution (LR) grid has 96 x 95 points corresponding to a resolution of $3.75^{\circ}$ longitude $\mathrm{x} 1.875^{\circ}$ latitude and the Medium Resolution (MR) version has $144 \times 143$ points, with a resolution of $2.5^{\circ}$ longitude $x 1.25^{\circ}$ latitude.

\section{Design of LMDZ4 experiments}

The $20^{\text {th }}$ century experiments consist of one set (HIST1, HISTNAT1) of long simulations for the period 1886-2005, and another set (HIST2, HISTNAT2) for a shorter period 1951-2005. The HIST1 and HIST2 experiments include both natural (varying solar-irradiance and volcanicaerosols) and anthropogenic (GHG, aerosols, ozone and land-use changes) forcing, while HISTNAT1 and HISTNAT2 include natural forcing only. Each of these experiments is a single member realization. We also performed a future projection following the RepresentativeConcentration-Pathway-4.5 (RCP4.5) scenario spanning 2006-2095. To distinguish the effects of GHG and non-GHG forcing, we performed two sets of decadal time-slice experiments (HIST1_GHG and HIST1_PIGHG) for 1951-1960, 1961-1970, 1971-1980, 1981-1990 and 1991-2000 respectively². A two-year spin-up is performed before starting the decadal time-slice integrations so as to avoid possible shocks from restarts (e.g. the 1951-1960 experiment was initiated from January 1949). The HIST1_GHG time-slices account for observed time-varying GHG-forcing only, but land-use and aerosol distributions are set to the 1886 values. The HIST1_PIGHG employs varying land-use and aerosol distributions, but fixed GHG

\footnotetext{
${ }^{2}$ The high-resolution LMDZ4 simulations with zooming over South Asia are computationally intensive and timeconsuming. Therefore, the HIST1_GHG and HIST1_PIGHG time-slice simulations across different decades were performed in parallel.
} 
214 concentration corresponding to 1886. To confirm the robustness of results, we employed two

215 cumulus convection parameterization schemes for the historical simulations. The (HIST1 and

216 HISTNAT1) simulations are based on the Emanuel scheme (Emanuel, 1993), while the (HIST2

217 and HISTNAT2) simulations use the Tiedtke scheme (Tiedtke, 1989). All the other experiments

218 used Emanuel convection. A summary of all the experiments is provided in Table 2.

219

220

221

222

223

224

225

226

227

228

229

230

231

233

234

235

236

237

.

\subsection{Forcing used in the LMDZ4 experiments}

Global $\mathrm{CO}_{2}$ concentration is directly prescribed in the simulations from 1886 to 2095 for computing radiative budget. $\mathrm{CO}_{2}$ concentration for the period 1886-2005 is derived from the Law Dome ice core, the Mauna Loa and the NOAA global-mean records. From 2006 onwards, $\mathrm{CO}_{2}$ emissions and concentrations are projected by Integrated Assessment Models and Carbon Cycle - Climate models (Dufresne et al. 2013). In the RCP4.5 scenario, the radiative forcing at the end of 2100 is $4.5 \mathrm{Wm}^{-2}$ and $\mathrm{CO}_{2}$ concentration stabilizes at $543 \mathrm{ppmv}$ in 2150 . The concentration of other GHGs like $\mathrm{CH} 4, \mathrm{~N} 2 \mathrm{O}, \mathrm{CFC}-11$ and $\mathrm{CFC}-12$ are directly prescribed in the model radiative code based on the recommended CMIP5 datasets (Dufresne et al. 2013).

232

231

33

2011). Time-varying distributions of SST used in the simulations are derived from the IPSL-

CM5 coupled-model projections. The SST boundary-forcing in LMDZ4 experiments is basically constructed by superposing the SST anomalies from the IPSL-CM5A-LR simulations on the observed climatological mean SST from AMIP (Taylor et al. 2013). This approach retains the realism of climatological mean SST and also overcomes the limitation of prescribing raw SSTs 
warranted by limited-area models. Note that the SST anomalies for the different LMDZ4 experiments (i.e., HIST, HISTNAT, RCP4.5 HIST_GHG) come from the corresponding IPSL-CM5A-LR simulations (Table.2). The same procedure is also used for specifying sea-ice boundary conditions.

Time-varying 3-dimensional distributions of ozone, natural aerosols (e.g., seasalt, dust) and anthropogenic aerosols (e.g., sulfates, black carbon, particulate organic matter) and gaseous reactive species are prescribed in the LMDZ4 experiments. These fields come from the IPSL-CM5A-LR simulations coupled to the Interaction with Chemistry and Aerosol (INCA) model (Szopa et al. 2013). In addition, the LMDZ4 simulations are directly forced by time-varying total solar irradiance (Lean et al. 2009) and volcanic radiative-forcing for past periods. For the future, it is assumed that the solar cycles repeat identical to the last cycle (cycle 23) with solar irradiance values from 1996 to 2008. The volcanic forcing is held constant for the future scenarios (Dufresne et al. 2013). Note that the present LMDZ4 simulations take into account the impact of prescribed aerosols on precipitation through large-scale radiative forcing, but the aerosol transports are not explictly computed. Fully coupled / interactive aerosol-climate simulations with the zoom configuration are currently beyond reach, here we wanted to focus on the importance of climate change on the regional-scale SAM and to understand the mechanisms involved. This is the reason for choosing the high-resolution zoomed model configuration at the expense of ensemble realizations and aerosol coupling. Furthermore, a recent study indicates that differences in the LMDZ simulations between prescribed aerosols versus interactively computed aerosols have little impact in terms of radiation and radiative forcing (Deandreis et al. 2012). 


\section{Analysis of observed and simulated changes in SAM during recent decades}

264

265

266

\subsection{Long-term trends in seasonal monsoon rainfall}

We employed two approaches to determine long-term trends in the seasonal monsoon rainfall and their statistical-significance. The first method estimates trends using linear least-square fit and a two-tailed student's t-test for statistical-significance ( $\mathrm{P}$ values). Table 1 provides a summary of observed and simulated trends in the June-September (JJAS) seasonal rainfall averaged over the Indian land region $70-90^{\circ} \mathrm{E}, 10-28^{\circ} \mathrm{N}$ during $1951-2005$ and for the $21^{\text {st }}$ century following RCP4.5. The second method, based on the locally weighted polynomial regression (LOESS) technique, fits the data locally in segments and does not require specification of a global function for fitting a model to the data (Cleveland and Devlin 1988). The fit of local polynomial to each subset of the data uses weighted linear least-squares of firstdegree. The "bandwidth", which determines the data-length for fitting each local first-degree polynomial, is set to 35 years. The LOESS trends are estimated for the observed and simulated SAM rainfall time-series, including simulations from 21 CMIP5 models (Table 3). Finally, the local (in time) standard-deviations estimated from the CMIP5 trends are computed and plotted to assess the significance of monsoon rainfall trends.

It is interesting to note that the HIST1 and HIST2 simulations capture both the observed mean and decreasing trend of monsoon precipitation during later part of the $20^{\text {th }}$ century (Figs.1a,2,3,4). The coarse-resolution IPSL-CM5A-LR (Fig.2d) and most of the CMIP5 coupled models fail to simulate the decreasing trend of SAM precipitation (e.g. Saha et al. 2014). Note that HIST1 and HIST2 show a significant $(\mathrm{P}<0.01)$ reduction of monsoon rainfall over the Indian land region during 1951-2005 by $\sim 16 \%$ and $\sim 9 \%$, respectively (Table 1, Figs.2-3). The 
magnitude of the simulated rainfall trends is higher, particularly in HIST1, relative to the observed rainfall decline $(\sim 7 \%)$. The prominence of the monsoon precipitation decline also manifests in the LOESS trends in observations and LMDZ4, which clearly lie outside the range of the CMIP5 trends (Fig.4). While the overall shape of the time-varying LOESS trends in HIST1 is similar to that of the observations, the simulated amplitude is relatively larger than the observed (Fig.4). Also notice that the declining trend, which starts from 1950s in observations and late 1930s in HIST1, continues till the end of the $20^{\text {th }}$ century. Furthermore, attribution of the declining SAM rainfall to human influence is clearly supported by the absence of statisticallysignificant trends in HISTNAT1 and HISTNAT2 (Fig.3, Table.1). The RCP4.5 projection from LMDZ4 indicates a further decline of SAM rainfall and persistence of drought conditions during coming decades (Fig.1a), which is contrary to the precipitation increase projected by the ensemble-mean of CMIP5 models with large inter-model spread (Chaturvedi et al. 2013, Saha et al. 2014, Sharmila et al. 2014).

\subsection{Long-term trends in aridity}

With rising surface temperatures and declining seasonal monsoon rains, aridity tends to be more severe due to higher rates of potential evapotranspiration (Kumar et al. 2013; Vicente-Serrano, et al. 2013; Thornthwaite, 1948). We examined aridity variations using the Standardized Precipitation-Evapotransipiration Index (SPEI), from LMDZ4 simulations and observations computed using the IMD rainfall (Pai et al. 2014) and CRU surface air-temperature (Fig.1b). SPEI is an indicator of the spatio-temporal variability of droughts that considers the combined effects of precipitation and temperature (via., evaporative demand) on droughts (Kumar et al. 2013; Vicente-Serrano et al. 2013). It is based on a difference between monthly precipitation (P in $\mathrm{mm}$ ) and monthly Potential Evapotranspiration (PET in $\mathrm{mm}$ ), calculated for different time- 
scales. SPEI is particularly suited for studying the effects of long time-scale droughts $(>3$ months) on hydrological and ecological systems (Vicente-Serrano et al. 2013). The calculation of PET is based on the Thornthwaite's method, which requires only data of monthly mean temperature. The difference $\mathrm{D}=\mathrm{P}-\mathrm{PET}$ is then accumulated for various time-scales,

$$
D_{n}^{k}=\sum_{i=0}^{k-1}\left(P_{n-i}-P E T_{n-i}\right), \quad n \geq k
$$

where (k months) is the accumulation timescale and ' $\mathrm{n}$ ' is the calculation index. The $\mathrm{D}$ values are undefined for $\mathrm{k}>\mathrm{n}$. In calculating SPEI, a log-logistic probability distribution function is used to fit the data-series of D and standardized (Vicente-Serrano et al. 2013). Values of SPEI < -0.5 represent moderate-droughts (Kumar et al. 2013), and SPEI $<-1.5$ indicates severe-drought conditions. A marked increase in the propensity of monsoon-droughts is seen during the post1950s in HIST1 and HIST2 (Fig.1b), which is congruent with observations (Kumar et al. 2013). We have also noted that the SPEI index at 12-month and 24-month time-scales in HIST1 and HIST2 exhibits clear decreasing trends during (1951-2005), which are absent in the HISTNAT1 and HISTNAT2 simulations (figures not shown).

\subsection{Long-term trends in frequency daily precipitation extremes}

A significant rise in the frequency of heavy-precipitation events (intensity $\geq 100 \mathrm{~mm} \mathrm{day}^{-1}$ ) over Central India is reported to have occurred during recent decades (Goswami et al. 2006). Using daily rainfall from observations and LMDZ4 simulations, we counted the number of heavyprecipitation events over Central India $\left(74.5^{\circ}-86.5^{\circ} \mathrm{E}, 16.5^{\circ}-26.5^{\circ} \mathrm{N}\right)$ having rainfall intensity $\geq$ $100 \mathrm{~mm} \mathrm{day}^{-1}$. The counts were determined for the JJAS season (122 days) of each year, so as to produce year-wise time-series of frequency-count of heavy-precipitation events over Central India (Fig.1c). An assessment of linear trends in these time-series during 1951-2005 and their 
statistical significance is presented in Table.4 (see Auxiliary Fig.A1). Significant $(\mathrm{P}<0.01)$ increases in the frequency of heavy-precipitation occurrences are seen in observations $(\sim 30 \%)$ and the HIST1 ( 30\%) and HIST2 ( 42\%) simulations; but not in HISTNAT1 and HISTNAT2. Also the future projection under RCP4.5 shows further increase in the frequency of such heavyprecipitation events. It must be mentioned that the robust increase of heavy-precipitation occurrences in the monsoon region in HIST1 and HIST2 (Fig.1c) is an important value-addition from the use of high-resolution, especially given that the statistics of monsoon precipitation extremes and their changes are rather poorly captured by the CMIP models (Turner and Slingo 2009, Chaturvedi et al. 2012). The rising trend of heavy precipitation occurrences in the backdrop of a weakening large-scale SAM will be taken up for discussion later.

\section{Attribution of monsoon weakening to anthropogenic forcing}

Figure 5 shows difference maps (HIST1 minus HISTNAT1) of mean JJAS rainfall and $850 \mathrm{hPa}$ winds for the period 1951-2005. The widespread and significant $(\mathrm{P}<0.05)$ decrease of the simulated monsoon rainfall over the Indo-Gangetic plains and the mountainous west coast provides a basis for attributing the recent SAM weakening to anthropogenic-forcing (Fig.5). A clear weakening of the large-scale monsoon circulation is evident from the anticyclonic pattern with anomalous easterly winds extending far into the Arabian Sea. The precipitation enhancement and associated circulation anomalies over the Himalayan foothills, near-equatorial Indian Ocean, downstream areas of Indo-China and Southeastern China (Fig.5) are reminiscent of 'monsoon-breaks' over India (e.g. Krishnan et al. 2000). Interestingly, the downstream precipitation enhancement seen over Southeastern China in the LMDZ4 simulations (Fig.5) and was not captured in the aerosol-forced response of Bollasina et al. (2011). Consistent with observed pattern of rainfall trends (see Chung and Ramanathan, 2006), the simulations also 
display anomalous rainfall deficits over northeastern China and West-African Sahel, with the latter being linked to SST-warming in the equatorial Indian and Atlantic Oceans (Giannini et al. 2003) and SST variations in the tropical Pacific (Semazzi et al. 1988). A further reduction of monsoon rainfall over north-central parts of India is noted in the RCP4.5 projection in the nearfuture (see Auxiliary Fig.A2).

\subsection{Distinguishing the mean monsoon response to GHG and non-GHG forcing}

To differentiate the effects of GHG versus non-GHG forcing, we examined the HIST1_GHG and HIST1_PIGHG experiments. We compared the JJAS mean rainfall and $850 \mathrm{hPa}$ winds from these two simulations with HISTNAT1 for the 5 decadal time-slices (1951-1960), (1961-1970), (1971-1980), (1981-1990) and (1991-2000). An anomalous decrease of monsoon rainfall over the Indian landmass and weakening of monsoon circulation is noted in the (HIST1_PIGHG minus HISTNAT1) difference maps for the 5 decadal time-slices (figure not shown); whereas the (HIST1_GHG minus HISTNAT1) difference showed anomalous intensification of monsoon circulation and rainfall over the Indian subcontinent (see Fig.6b). Figure.6 illustrates the decomposition of the SAM response to GHG and non-GHG forcing using difference maps composited for the period (1951-2000). For example, the difference $\delta($ No_GHG) $=($ HIST1 minus HIST1_GHG) considers the effect of all forcing, except GHG, including the SST response and internal variability. In this case, a prominent weakening of the monsoon circulation and rainfall reduction over India can be noted in HIST1 relative to HIST1_GHG (Fig.6a). On the other hand the effect of GHG-forcing, including the SST response to GHG-forcing, is borne out in the difference $\delta(\mathrm{GHG})=($ HIST1_GHG minus HISTNAT1) map (Fig.6b) which shows a prominent intensification of monsoon rainfall and circulation. The difference $\delta\left(G H G \_A t m o s\right)=$ (HIST1 minus HIST1_PIGHG) represents the atmospheric radiative effect of GHG-forcing with 
imposed SSTs. In this case, a slight weakening of monsoon flow and small rainfall decrease is seen (Fig.6c), indicative of a possible increase of static-stability due to rapid increase of moisture in a warming world. This point will be discussed again later. The difference map in Fig.6d $\left[\delta\left(\mathrm{GHG}_{-} \mathrm{SST}\right)=\delta(\mathrm{GHG})\right.$ minus $\left.\delta\left(\mathrm{GHG}_{-} \mathrm{Atmos}\right)\right]$ indicates the effect of SST changes only due to GHG increase plus the internal variability of SSTs. An intensification of monsoon circulation and rainfall is prominently seen in this case, which is apparently linked to the pronounced SST warming $\left(\sim 1^{\circ} \mathrm{C}\right)$ in the north-central Arabian Sea and north Bay of Bengal in HIST1_GHG (figure not shown). Also the contrasting monsoonal responses in HIST1_GHG and HIST1_PIGHG are indicative of the impact of non-GHG forcing on the recent SAM weakening.

\section{Non-GHG forcing and SAM weakening}

Several studies have linked the recent SAM weakening to increases in anthropogenic aerosols (eg., Ramanathan et al. 2005, Chung and Ramanathan, 2006, Meehl et al. 2008, Bollasina et al. 2011, Ganguly et al. 2012, Salzmann et al. 2014, Sanap et al. 2015). The aerosol direct-radiative effect which causes reduction of surface insolation ("solar-dimming") through scattering and absorption can weaken the SAM through a variety of mechanisms viz., decrease of meridional sea-surface-temperature (SST) gradient between equator and $25^{\circ} \mathrm{N}$ (Ramanathan et al. 2005; Meehl et al. 2008), inter-hemispheric energy imbalance (Bollasina et al. 2011), weakening of tropospheric-temperature gradient and vertical wind-shear (Ganguly et al. 2012), decrease of water vapor availability (Salzmann et al. 2014), surface cooling over the Indian subcontinent (Sanap et al. 2015) and so on. Here, we discuss on the temporal evolution of the major regionalforcing elements and the SAM response from the (HIST1 + RCP4.5) simulations (Fig.7).

\subsection{Regional land-use change}


The South and Southeast Asian region experienced significant land-use and land-cover changes during the $19^{\text {th }}$ and $20^{\text {th }}$ centuries (Flint and Richards 1991; Ramankutty et al. 2006; Hurtt et al. 2011). The time-evolution of tree-fraction, crop-fraction and planetary albedo averaged over the Indian land region $\left(70^{\circ} \mathrm{E}-90^{\circ} \mathrm{E} ; 10^{\circ} \mathrm{N}-28^{\circ} \mathrm{N}\right)$ is presented in Fig.7a. In addition, spatial maps of tree-fraction/crop-fraction during 1951-2000 are provided in Figs.8a-b and the corresponding difference [(1891-1930) minus (1951-2000)] maps in Figs.8c-d. We note from Fig.7a that the crop-fraction over India increased by about $45 \%$ and tree-fraction declined by about $30 \%$ during 1886-2005. This is consistent with earlier reports of crop-area change over the region, which expanded by $\sim 45 \%$ at the expense of all natural vegetation types (Flint and Richards 1991, Ramankutty et al. 2006). Also note that the RCP4.5 scenario allows for a partial recovery of treefraction from 2030s (Fig.7a). From Fig.8, one can notice that the expansion (contraction) of crop-area (tree-area) during (1951-2000) relative to (1891-1930) is seen across various parts of South and Southeast Asia. Interestingly, the time-series of simulated regional planetary-albedo shows an increasing trend from 1886 to mid-1980s, and a near-stationary pattern until 2040s, followed by a slight decrease thereafter (Fig.7a). The overall increase in regional planetaryalbedo (including cloud effects) during the period 1886-2005 is 9\%. Further, note that the decrease (increase) of crop-fraction (tree- fraction) in the late $21^{\text {st }}$ century proceeds rather gradually as compared to the faster rate of change [with opposite sign] in the early $20^{\text {th }}$ century. This is also reflected in the gradual decrease of the simulated regional planetary-albedo variations in the late $21^{\text {st }}$ century.

\subsection{Anthropogenic aerosol-forcing}

The time-evolution of the simulated anthropogenic aerosol-forcing at the top-of-atmosphere (TOA) averaged over the Indian region is shown in Fig.7b. The TOA aerosol radiative forcing 
ranges between -0.8 and $-1.6 \mathrm{Wm}^{-2}$ during 1960s and mid-2020s, and becomes less negative after 2020s (Fig.7b). Although, the RCP4.5 scenario considers abatement of emissions, note that the projected aerosol-forcing (negative) continues till 2050. Spatial maps of the simulated anthropogenic aerosol-forcing at the TOA and the atmospheric absorption (i.e., difference in aerosol-forcing [TOA minus surface]) from HIST1 during (1951-2005) are shown in Fig.9. Note that the simulated TOA aerosol-forcing is about $-2 \mathrm{Wm}^{-2}$ over north-central India and larger (about $-4 \mathrm{Wm}^{-2}$ ) over east-central China (Fig.9a). The simulated atmospheric absorption is high (3-4 $\left.\mathrm{Wm}^{-2}\right)$ over north India and maximum $\left(>6 \mathrm{Wm}^{-2}\right.$ ) over east-central China (Fig.9b). Ramanathan et al. (2005) and Chung and Ramanathan (2006) argued that the declining trend of SAM rainfall is largely due to increasing emissions of absorbing aerosols (e.g. black carbon) over the Asian region. On the other hand, Bollasina et al. (2011) propose that the recent SAM weakening is influenced largely by increase of sulfate aerosols (scattering-type) in the NH. An examination of aerosol optical depths at $500 \mathrm{~nm}$ from the HIST1 simulation, for both black carbon and sulfate, revealed that both species have large contributions to anthropogenic aerosolforcing over East Asia, while black-carbon contribution is significant over the South Asian region and sulfate contribution is significant over central Eurasia (figure not shown).

Both land-use change and aerosol-forcing can influence the SAM through changes in regional planetary-albedo (Lenton et al. 2008). Given the reflectivity differences between absorbing and scattering aerosol-types, increases in absorbing aerosols need not necessarily lead to increase of planetary-albedo. The marginal increase in the simulated regional planetary-albedo after mid-1980s (Fig.7a) is more indicative of radiative effects from absorbing-aerosols. We also note that the increase of atmospheric absorption over the Indian region is associated with increased atmospheric stability in HIST1 during the post-1950s (figure not shown). As discussed 
453 before, the main point from Fig.7a is that the combined effects of land-use change and

454 anthropogenic aerosol-forcing apparently yield an overall increase in regional planetary-albedo

455 during the historical period. Increases in planetary-albedo can reduce precipitation through 456 compensating subsidence required to maintain thermal equilibrium (Charney 1975). This albedo-

457 precipitation feedback is substantiated in the simulated decrease of SAM rains during the 458 second-half of the $20^{\text {th }}$ century and in the future (Auxiliary Fig.A2).

459

460

461

462

463

464

465

466

467

468

469

470

471

472

473

474

475

476

\subsection{Equatorial Indian Ocean SST warming signal}

Another major regional signal is the warming of equatorial IOSST, by $0.5^{\circ}-1^{\circ} \mathrm{C}$ during the last few decades, and projected to continue through the $21^{\text {st }}$ century (Figs.7b, 10). While drivers such as aerosols or GHGs are independent forcing which can drive SST and atmospheric circulation changes, our focus here is on the fact that changes in surface winds can in turn alter SST through oceanic processes, and are taken into account in the CMIP coupled models (see Fig.10). For example the recent equatorial IOSST warming trend, which is in excess of the global-warming signal (Fig.10c), is a dynamical response of the Indian Ocean to changing monsoonal winds (Swapna et al. 2013). Mishra et al. (2012) analyzed coupled patterns of observed SST and Indian monsoon rainfall variability for the $20^{\text {th }}$ century using maximal covariance analysis. The second mode of variability from their analysis suggests a linkage between the recent decreasing trend of monsoon rainfall over the Indo-Gangetic plains and the equatorial IOSST warming signal and this has also been pointed out by other investigators (e.g., Krishnan et al. 2013, Abish et al. 2013, Swapna et al. 2013, Roxy et al. 2015). The connection between the declining monsoon rains and IOSST warming signal is clearly borne out by the precipitation increase in the near-equatorial region in the HIST1 simulation (Fig.5). 


\subsection{Weakening of SAM circulation and hydrological consequences}

The temporal evolution of the SAM response in HIST1 shows a clear increasing trend of sealevel pressure (SLP) over the Indian region during the recent few decades and is supported by the observed SLP trend (Fig.7c). On the other hand, the HISTNAT1 simulation does not exhibit any long-term trend in the SLP variations. Also note that the simulated SLP increase in the $21^{\text {st }}$ century in Fig.7c is consistent with the likely projected decline of SAM rainfall in future. Furthermore, the SAM weakening in the HIST1+RCP4.5 simulation is corroborated by the decreasing trend of the easterly vertical-shear of zonal-winds (Fig.7e).

A sustained weakening of monsoon in a warming environment has direct hydrological consequences (Kumar et al. 2013). On multi-decadal and centennial time-scales, soil moistureclimate feedbacks can also induce vegetation shifts and contribute to climate change (Seneviratne et al. 2010). Note that the HIST1 simulation indicates depletion of soil-moisture by 23\% during 1886-2095 (Fig.7f). Persistence of soil-moisture deficiencies over the SAM region, an identified hot-spot of land-atmosphere coupling to precipitation (Koster et al. 2004), can in turn reduce evapotranspiration particularly in soil-moisture limited regimes and semi-arid transition zones (e.g. Manabe and Delworth 1990, Koster et al. 2004, Seneviratne et al. 2010) and impact crop-production. In a recent study by Ramarao et al. (2015), we analyzed the landsurface response over the Indian region to changing monsoon precipitation by means of the LMDZ4/HIST1 simulations and noted that a 5\% depletion of soil-moisture during (1951-2005) resulted in a decrease of evaportranspiration by nearly $10 \%$ (figure not shown).

\subsection{Changes in moderate and heavy precipitation occurrences over the SAM region}


Another critical hydrological ramification comes from the rising trend in the frequency and intensity of daily precipitation extremes, which are expected to increase over several regions of the world in response to global warming (Toreti et al. 2013). It is noted from the HIST1 simulation that the surface warming over the Indian region during (1886-2005) is over $2^{\circ} \mathrm{C}$ (figure not shown) and correspondingly the simulated moisture-content over the Indian region increased by $\sim 24 \%$ during this period (Fig.7d). Rising humidity levels over the Indian region can also be confirmed from surface specific-humidity observations, which are available from early 1970s (figure not shown). In the SAM context, increases in heavy precipitation (intensity > 100 $\mathrm{mm}$ day $^{-1}$ ) occurrences over Central India have happened at the expense of moderate events (5 $\mathrm{mm}$ day $^{-1} \leq$ rainfall intensity $<100 \mathrm{~mm} \mathrm{day}^{-1}$ ), with the latter having declined significantly since 1950s (Goswami et al. 2006, Rajeevan et al. 2008).

Here, we examine changes in the distribution of heavy and moderate monsoon precipitation due to GHG and regional-forcing elements, respectively. For this purpose, we analyze year-wise frequency-counts of heavy and moderate daily precipitation events over Central India $\left(74.5^{\circ}-86.5^{\circ} \mathrm{E}, 16.5^{\circ}-26.5^{\circ} \mathrm{N}\right)$ during $1951-2000$ from HIST1 and HIST1_GHG and compared them to the frequency-count in HISTNAT1 (see Fig.11). Year-wise counts were calculated for each JJAS season (122 days) during the entire 50-year period. Changes in frequency-count were computed relative to the mean-counts of heavy and moderate precipitation-types from HISTNAT1 averaged for the period (1951-2000). Fig.11 shows boxwhisker plots based on distributions of changes in yearly counts of moderate and heavy precipitation events over Central India from HIST1 and HIST1_GHG. It is interesting to note that HIST1 captures the contrasting change of the frequency-counts between the moderate and heavy precipitation types, whereas the frequency-count of both categories increases in 
HIST1_GHG. With regard to changes in the heavy-precipitation category, notice that the median (i.e., second quartile $\mathrm{Q}_{2}$ ) is nearly the same for both HIST1 and HIST1_GHG; although the third quartile $\left(\mathrm{Q}_{3}\right)$ is significantly higher in HIST1 as compared to HIST1_GHG (Fig.11). This suggests that the surplus of heavy precipitation in HIST1 is basically contributed by very intense precipitation events. Given that increase of moisture is common to both HIST1 and HIST1_GHG, the increase of more number of intense precipitation events in HIST1 is attributable to enhancement of deep localized convection, which is more likely in an atmosphere with weak vertical-shear of the SAM circulation (e.g. Romatschke and Houze 2011). Conversely, a weak SAM circulation with depleted vertical-shear inhibits organization of mesoscale convective systems and suppresses monsoonal rains in the moderate category (Stano et al. 2002). These discussions suggest that increase of atmospheric moisture (Fig.7d) and decrease of easterly vertical shear of the SAM circulation (Fig.7e) in HIST1 provide conditions favorable for localized heavy precipitation occurrences at the expense of moderate monsoonal rains.

\section{Physical mechanism of weakening of SAM}

Based on the present results, it is suggested that the physical mechanism for the recent decline of SAM precipitation is rendered through a slowdown of the monsoon meridional overturning circulation in response to the regional-forcing elements. The HIST1 simulations reveal that land use changes and anthropogenic aerosol-forcing over South Asia have significantly enhanced the regional planetary-albedo. Dynamical constraints for maintaining thermal equilibrium are supported by subsidence induced by the near-equatorial precipitation anomalies associated with the IOSST warming signal. Figure.12a shows anomalous subsidence over the Indian landmass, together with near-equatorial ascending motions, indicating weakening of the monsoon 
547 meridional overturning circulation in HIST1 relative to HISTNAT1. Further, this suppressed 548 convection over the subcontinent facilitates anomalous interactions of the monsoon and 549 midlatitude circulations and sets up large-scale quasi-stationary anomalies in the middle and 550 upper-troposphere, so that sinking of cold and dry northwesterly winds in turn can suppress 551 precipitation leading to prolonged dry conditions over the subcontinent (Auxiliary Fig.A3, see

552 also Krishnan et al. 2009, Krishnamurti et al. 2010). The equatorial tropospheric warming 553 (Auxiliary Fig.A3) is in part associated with the IOSST warming signal and also due to an 554 555 556 557 558

overall increase in tropical condensational heating in HIST1. With continued equatorial IOSST warming, the RCP4.5 projection indicates persistence of anomalous ascending (descending) motions in the near-equatorial region (Indian subcontinent) in the coming decades (Fig.12b).

\section{Value additions from high-resolution}

Here, we discuss value additions from the high-resolution SAM simulations using LMDZ4 vis-àvis the coarse-resolution IPSL-CM5A model.

\subsection{Resolving the monsoon orographic precipitation over the Western Ghats}

The narrow Western Ghats (WG) escarpment is an important topographic feature that runs for over $1600 \mathrm{~km}$ almost parallel to the Arabian Sea with highest peaks having altitudes greater than 2600 m (Kale 2010; Xie et al. 2006). Impingement of monsoon southwesterly winds forces moist air ascent over the windward slopes of the WG, causing substantial precipitation as much as $3000 \mathrm{~mm}$ in the monsoon season (Xie et al. 2006), and the associated latent heat of condensation estimated from satellite measurements is around 3-4 $\mathrm{K}$ day $^{-1}$ (Choudhury and Krishnan, 2011). High-resolution is very important to capture the mean monsoon orographic precipitation along the WG and Himalayan foothills, and also to resolve moisture-gradients across the Indo-Pak and 
571 Hindu-Kush mountainous region for supporting moist convective processes over the Indo-

572 Gangetic plains (Sabin et al. 2013). Improvements in the WG orographic precipitation in

573 LMDZ4 relative to the IPSL-CM5A models are clearly seen from (Auxiliary Fig.A4). Mean and

574 standard-deviation values of JJAS rainfall averaged over the Western Ghats $\left(72^{\circ}-76^{\circ} \mathrm{E}, 10^{\circ}\right.$ -

$\left.57519^{\circ} \mathrm{N}\right)$ and Indian land region $\left(70^{\circ}-90^{\circ} \mathrm{E}, 10^{\circ}-28^{\circ} \mathrm{N}\right)$ from GPCP, LMDZ4, IPSL-CM5A-LR and

576 IPSL-CM5A-MR are given in Table.5. Also shown is information about $850 \mathrm{hPa}$ monsoon zonal

577 winds, averaged over a broader region $\left(5^{\circ} \mathrm{N}-22^{\circ} \mathrm{N}, 55^{\circ} \mathrm{E}-90^{\circ} \mathrm{E}\right)$ around India. Note that the

578 magnitudes of mean precipitation and zonal winds are considerably underestimated in the IPSL-

579 CM5A models, whereas LMDZ4 shows closer agreement with observations (Table.5). It is to be

580 also noted that the variability of monsoon winds and precipitation is stronger in LMDZ4 relative

581 to the IPSL-CM5A models.The differences in mean precipitation over Central India between

582 HIST1 and HIST2 (Auxiliary Fig.A4) are indicative of the strong internal variability of SAM

583 (Salzmann et al. 2014) and the sensitivity of precipitation simulation to choice of cumulus

584 convection scheme (i.e., Emanuel in HIST1 / Tiedtke in HIST2). However, note that the JJAS

585 mean rainfall averaged over the larger land region is comparable in HIST1 (6.9 mm day $\left.{ }^{-1}\right)$ and

586 HIST2 $\left(6.3 \mathrm{~mm} \mathrm{day}^{-1}\right)$. Also both HIST1 and HIST2 show decreasing trends of monsoon

587 precipitation averaged over the larger land region, despite sub-regional scale differences. We

588 have also confirmed the weakening trend of low-level monsoon winds in HIST1, HIST2 and

589 NCEP reanalysis during 1951-2005 (figure not shown). In a recent separate study by Ramarao et

590 al. (2015), we note that the high resolution LMDZ4 simulation significantly improves the

591 climatological surface hydrological balance between Runoff (R) and Precipitation minus

592 Evapotranspiration (P-ET) over the over the Indian land region as compared to the IPSL coarse

593 resolution model. Another prominent feature of the high-resolution simulation is the anomalous 
594 precipitation enhancement near the eastern Himalayan foothills and downstream areas of Indo-

595 China (Fig.5), emerging from interplay between large-scale and regional-scale circulation 596 dynamics and mesoscale orographic amplification (Vellore et al. 2014).

597

598

599

600

601

602

603

604

605

606

607

608

609

610

611

612

613

614

615

616

617

\subsection{Coupling of monsoon precipitation and wind variations under changing climate}

Monsoon precipitation variability over the WGs is closely linked to strength of the monsoon low-winds over the Arabian Sea (Krishnamurti and Bhalme 1976; Joseph and Sabin 2008). Strong southwesterly winds (wind speed $>20 \mathrm{~ms}^{-1}$ ) favor enhanced precipitation, so that latent heating in turn strengthens the winds and forces upward motions over the WG and the Arakan Yoma in Myanmar (e.g. Xie et al. 2006; Choudhury and Krishnan 2011; Sabin et al. 2013). We examined the coupling between monsoon precipitation and low-level winds using observations, the LMDZ4 and IPSL-CM5A-LR models. We first performed an Empirical Orthogonal Function (EOF) / Principal Component (PC) analysis of JJAS rainfall over the WGs and Peninsular India during (1951-2005) using observations (APHRODITE), the LMDZ4/HIST1 and IPSL-CM5ALR simulations. Later, the PC1 index of rainfall was regressed on the $850 \mathrm{hPa}$ winds. The leading EOF/PC and regression of wind pattern are shown in Auxiliary Fig. A5. The leading PC time-series shows a decreasing trend in APRHODITE and LMDZ4/HIST1; and wind regression shows a westerly pattern implying a positive correlation between the declining WG rainfall and monsoon low-level circulation during (1951-2005) - a period associated with significant globalwarming. In other words, the monsoon wind-precipitation connection is consistently seen in the high-resolution HIST1 simulation, but not in the coarse-resolution ISPL-CM5A-LR counterpart. In fact, the wind and precipitation variations are anti-correlated in the IPSL-CM5A-LR simulation, with the PC1 rainfall time-series not displaying a decreasing trend. 
Our understanding suggests that high-resolution is crucial for capturing the coupled variability of the WG orographic precipitation and large-scale monsoon winds. Basically, the internal variability of SAM rainfall is tied to both the monsoon circulation dynamics, as well as thermodynamical effects arising from radiative-convective feedbacks (Krishnamurti and Bhalme 1976). Most of the CMIP coarse-resolution models predominantly exhibit the thermodynamical sensitivity of the tropical/monsoonal response to global-warming, which results in enhancement of precipitation despite damping of the dynamical component (i.e., upward velocity, large-scale winds, horizontal-advection, etc) of monsoon circulation (see Kitoh et al. 1997; Douville et al. 2000; Veechi et al. 2006; Ueda et al. 2006; Cherchi et al. 2011). On the other hand, the highresolution LMDZ4 simulations better capture the wind-precipitation coupling, and thus a weakening of the monsoon flow induced by the regional-forcing leads to precipitation decrease over the Indian region.

\section{Concluding remarks}

Our findings suggest that the collaborative influence of regional land-use change, anthropogenicaerosol forcing and accelerated IOSST warming signal have conspired to weaken the SAM in recent decades. It must be pointed out that the realism of monsoon simulations in LMDZ4 and new insights gained from this study entail the use of high-resolution, which is crucial to resolve the interactions between the high orographic precipitation along the narrow Western Ghats and southwesterly monsoon winds. The high-resolution simulations also illustrate that the weakening of SAM circulation significantly alters the rainfall distribution over Central India by promoting surplus occurrences of intense localized precipitation events at the expense of moderate events. In this context, it may be mentioned that the coarse-resolution CMIP models have major 
641 shortcomings in detecting intense precipitation events and their changes particularly over the

642 SAM region (Chaturvedi et al. 2012) and the tropics in general (Toreti et al. 2013).

643

644

645

646

647

648

649

650

651

652

653

654

655

656

657

658

659

660

661

662

663

664

Sensitivity studies using a simple conceptual model of the monsoon (see Zickfeld et al. 2005; Lenton et al. 2008) suggest that increase of regional planetary-albedo, due to land-use change and/or aerosol forcing, beyond a critical threshold $(\sim 0.5)$ can potentially cause the Indian summer monsoon to pass a tipping-point, thereby completely altering the state of the monsoon. Although projected albedo variations (Fig.7a) are below this threshold, the hydrological-stress associated with declining monsoon rains is already severe (Kumar et al. 2013). It is noted that the projected monsoon rainfall tends to partly recover in later part of the $21^{\text {st }}$ century (Auxiliary Fig.A6), although drier conditions continue to prevail over the subcontinent. This leads to an important question, as to whether the SAM will recover in future. This possibility is still not clear especially in the light of the persistent equatorial IOSST warming signal. Observations and model simulations suggest that surface warming is often amplified in the tropical troposphere due to an overall increase in condensational heating by moist ascending air in regions of convection (Santer et al. 2008). This implies that, in addition to mitigating the effects of anthropogenic-aerosols and land-use changes, a slowdown of equatorial IOSST warming may hold the key for the SAM revival.

It is realized that the use of stand-alone atmospheric GCM can miss certain aspects of ocean-atmosphere coupling. On the other hand, it is known that the CMIP coupled models have large SST biases which can completely modify the monsoon and tropical circulation, leading to poor skills in capturing regional precipitation variability (Roehrig et al. 2013, He et al. 2014). In fact, atmospheric GCM simulations with imposed SST are reported to be far more realistic in 
665

666

667

668

669

670

671

672

673

674

675

676

677

678

679

680

681

682

683

684

685

686

687

688

capturing the observed decadal variations of the Sahel monsoon rainfall as compared to the CMIP5 coupled models (Roehrig et al. 2013). While errors due to lack of coupling are mostly related to internal variability, stand-alone atmospheric GCM simulations well reproduce circulation and precipitation response to long-term climate changes (He et al. 2014).

Bony et al. (2013) argue that robust tropical precipitation changes are associated with weaker radiative cooling in response to rising levels of carbon dioxide concentration, which affects the strength of the vertical component of atmospheric circulation. However, the findings from this study suggest that the decline of SAM circulation and precipitation in the latter half of the 20th century is largely attributable to changes in regional-forcing namely land-use changes, anthropogenic aerosols along with the equatorial IOSST warming signal, in addition to the GHGforcing. The combined effects of these elements tend to increase the regional planetary-albedo over the Indian subcontinent, resulting in weakening of monsoon meridional overturning circulation, decreased precipitation/convection and soil-moisture reduction. We also realize that remote-forcing (e.g., sulfate aerosol-emissions over Central Europe, long-range transports of pollutants over the Eurasian region, etc) can have implications on the large-scale Asian summer monsoon (e.g., Lelieveld et al. 2002, Cowan and Cai, 2011). However, it must be noted that the present simulations preclude us from separating the roles of the individual forcing components and drawing any inferences about the relative roles of regional and remote forcing on the SAM. Further investigations will also be necessary to better comprehend the role of soil-moisture feedbacks on monsoon precipitation.

Acknowledgments: The LMDZ4 simulations were performed on the IITM HPC. We thank Director, IITM for extending full support for this research. IITM receives full support from the 
689 Ministry of Earth Sciences, Government of India. We acknowledge Josefine Ghattas and 690 Sebastien Denvil from LMD/IPSL for computational support and M.V.S.Ramarao, CCCR for 691 analysis and technical support. We thank the Editor Prof. Jean-Claude Duplessy and the 692 anonymous reviewers for providing constructive comments. This work is partly supported by the 693 NORINDIA Project. 216576/e10.

694 


\section{References}

Abish B, Joseph PV, Johannessen OM (2013) Weakening trend of the tropical easterly jet stream of the boreal summer monsoon season 1950-2009. J Clim 26: 9408-9414 Adler RF et al (2003) The Version 2 Global Precipitation Climatology Project (GPCP) Monthly Precipitation Analysis (1979 - Present). J Hydrometeorol 4: 1147-1167

Allan R, Ansell T (2006) A new global complete monthly historical gridded mean sea level pressure dataset (HadSLP2): 1850-2004. J Clim 19: 5816-5842

Alory G, Meyers G (2009) Warming of the upper equatorial Indian Ocean and changes in the heat budget (1960-99). J Clim 22: 93-113

Annamalai H, Hamilton K, Sperber KR (2007) The South Asian summer monsoon and its relationship with ENSO in the IPCC AR4 simulations J Clim 20: 1071-1092

Bony S, Bellon G, Klocke D, Sherwood S, Fermepin S, Denvil S (2013) Robust direct effect of carbon dioxide on tropical circulation and regional precipitation. Nature Geosci 6: 447-451

Bookhagen B, Burbank DW (2010) Toward a complete Himalayan hydrological budget: Spatiotemporal distribution of snowmelt and rainfall and their impact on river discharge. $\mathbf{J}$ Geophys Res 115: F03019, doi: 10.1029/2009JF001426

Bollasina MA, Ming Y, Ramaswamy V (2011) Anthropogenic Aerosols and the Weakening of the South Asian summer monsoon. Science 334: 502-505

Charney JG (1975) Dynamics of deserts and droughts in the Sahel. Quart J Roy Meteorol Soc 101: $193-202$

Chaturvedi RK, Joshi J, Jayaraman M, Bala G, Ravindranath NH (2012) Multi-model climate change projections for India under representative concentration pathways. Curr Sci 103: 791-802

Cherchi A, Alessandri A, Masina S, Navarra A (2011) Effects of increased $\mathrm{CO}_{2}$ on monsoons. Clim Dyn 37: 83-101

Choudhury AD, Krishnan R (2011) Dynamical response of the South Asian monsoon trough to latent heating from stratiform and convective precipitation. J Atmos Sci 68: 1347-1363 
Chung CE, Ramanathan V (2006) Weakening of North Indian SST gradients and the monsoon rainfall in India and the Sahel. J Clim 19: 2036-2045

Cleveland WS, Devlin SJ (1988) Locally Weighted Regression: An approach to regression analysis by local fitting. J Amer Stat Association 83: 596-610

Cowan T, Cai W (2011) The impact of Asian and non-Asian anthropogenic aerosols on $20^{\text {th }}$ century Asian summer monsoon. Geophys Res Lett 38: L11703, doi:10.1029/ 2011GL047268

Deandreis C, Balkanski Y, Dufresne JL, Cozic A (2012) Radiative forcing estimates of sulfate aerosols in coupled climate-chemistry models with emphasis on the role of the temporal variability. Atmos Chem Phys, 12: 5583-5602

Douville H, Royer J-F, Polcher J, Cox P, Gedney N, Stephenson DB, Valdes PJ (2000) Impact of doubling $\mathrm{CO}_{2}$ on the Asian summer monsoon: robust versus model-dependent responses. J Meteorol Soc Japan $78: 421-439$

Dufresne JL et al (2013) Climate change projections using the IPSL-CM5 Earth System Model: from CMIP3 to CMIP5. Clim Dyn 40: 2123-2165

Emanuel KA (1993) A cumulus representation based on the episodic mixing model: the importance of mixing and microphysics in predicting humidity. AMS Meteorol Monographs 24 (46): 185-192

Fan F, Mann ME, Lee S, Evans JL (2010) Observed and modeled changes in the South Asian monsoon over the historical period. J Clim 23: 5193 - 5205

Flint EP, Richards JF (1991) Historical analysis of changes in land use and carbon stock of vegetation in South and Southeast Asia. Canadian J Forest Res 21: 91-110

Ganguly D, Rasch PJ, Wang H, Yoon J (2012) Fast and slow responses of the South Asian monsoon system to anthropogenic aerosols. Geophys Res Lett 39: L18804, doi:10.1029/2012GL053043

Gautam R, Hsu NC, Lau KM, Kafatos M (2009): Aerosol and rainfall variability over the Indian region: distributions, trends and coupling. Ann Geophys 27: 3691-3703

Giannini A, Saravanan R, Chang P (2003) Oceanic forcing of Sahel rainfall on interannual to interdecadal time scales. Science 302: 1027-1030 
Goswami BN, Venugopal V, Sengupta D, Madhusoodanan MS, Xavier PK (2006) Increasing trend of extreme rain events over India in a warming environment. Science 314: 1442-1445

Guhathakurta P, Rajeevan M (2008) Trends in the rainfall pattern over India. Int J Climatol 28: 1453-1469

Guo L, Turner AG, Highwood EJ (2015) Impacts of $20^{\text {th }}$ century aerosol emissions on the South Asian monsoon in the CMIP5 models. Atmos. Chem. Phys., 15: 6367-6378

Hasson S, Lucarini V, Pascale S (2013) Hydrological cycle over South and Southeast Asian river basins as simulated by PCMDI/CMIP3 experiments. Earth System Dynamics, 4: 199-217

He J, Soden BJ, Kirtman BP (2014) The robustness of the atmospheric circulation and precipitation response to future anthropogenic surface warming. Geophys Res Lett 41: 26142622

Hourdin F et al (2006) The LMDZ4 general circulation model: climate performance and sensitivity to parameterized physics with emphasis on tropical convection. Clim Dyn 27: 787813

Hsu PC, Li T, Luo JJ, Murakami H, Kitoh A, Zhao M (2012) Increase of global monsoon area and precipitation under global warming: a robust signal? Geophys Res Lett 39: L0670, http://dx.doi.org/10.1029/2012GL051037

Hurtt GC et al (2011) Harmonization of land-use scenarios for the period 1500-2100: 600 years of global gridded annual land-use transitions, wood harvest, and resulting secondary lands. Climatic Change 109: 117-161

Joseph PV, Sabin TP (2008) An ocean-atmosphere interaction mechanism for the active- break cycle of the Asian summer monsoon. Clim Dyn 30: 553-566

Joseph PV, Simon A (2005) Weakening trend of the southwest monsoon current through peninsular India from 1950 to the present. Curr Sci 89: 687-694

Kale V, (2010) Geomorphological Landscapes of the World. Ed. Piotr Migon, Springer 257

Kistler R et al (2001) The NCEP-NCAR 50-year reanalysis: Monthly means CD-ROM and documentation. Bull Amer Meteor Soc 82: 247-267 
Kitoh A et al (2013) Monsoons in a changing world: A regional perspective in a global context. J Geophys Res (Atmos) 118: 3053-3065

Kitoh A, Yukimoto S, Noda A, Motoi T (1997) Simulated changes in the Asian summer monsoon at times of increased atmospheric $\mathrm{CO}_{2} \cdot \mathrm{J}$ Met Soc Japan 75: 1019-1031

Koster RD et al (2004) Regions of strong coupling between soil moisture and precipitation. Science 305: 1138-1140

Krinner S et al (2005) A dynamic global vegetation model for studies of the coupled atmospherebiosphere system. Global Biogeochem Cycles 19(1): GB1015, doi: 10.1029/2003GB002199

Kripalani RH, Oh JH, Kulkarni A, Sabade SS, Chaudhari HS (2007) South Asian summer monsoon precipitation variability: coupled model simulations and projections under IPCC AR4. Theor Appl Climatol 90:133-159

Krishnamurti TN, Bhalme HN (1976) Oscillations of a monsoon system. Part I: Observational aspects. J Atmos Sci 33: 1937-1954

Krishnamurti TN, Martin A, Krishnamurti R, Simon A, Thomas A, Kumar V (2013) Impacts of enhanced $\mathrm{CCN}$ on the organization of convection and recent reduced counts of monsoon depressions. Clim Dyn 41:117-134

Krishnamurti TN, Thomas A, Simon A, Kumar V (2010) Desert air incursions, an overlooked aspect, for the dry spells of the Indian summer monsoon. J Atmos Sci 67: 3423-3441

Krishnan R et al (2013) Will the South Asian monsoon overturning circulation stabilize any further? Clim Dyn 40: 187-211

Krishnan R, Ramanathan V (2002) Evidence of surface cooling from absorbing aerosols. Geophy Res Lett 9: doi: 10.1029/2002GL014687

Krishnan R, Ramesh KV, Samala BK, Meyers G, Slingo JM, Fennessy MJ (2006) Indian OceanMonsoon coupled interactions and impending monsoon droughts. Geophys Res Lett 33: L08711 doi:10.1029/2006GL025811

Krishnan R, Vinay Kumar, Sugi M, Yoshimura J (2009) Internal feedbacks from monsoonmidlatitude interactions during droughts in the Indian summer monsoon. J Atmos Sci 66: 553578 
804 Krishnan R, Zhang C, Sugi M (2000) Dynamics of breaks in the Indian summer monsoon. J 805 Atmos Sci 57: 1354-1372

806 Kumar KN, Rajeevan M, Pai DS, Srivastava AK, Preethi B (2013) On the observed variability of 807 monsoon droughts over India. Weather and Climate Extremes 1: 42-50

808 Lau WKM, Wu HT, Kim KM (2013) A canonical response of precipitation characteristics to 809 global warming from CMIP5 models. Geophys Res Lett 40: 3163-316

810 Lean J (2009) http://www.geo.fu-berlin.de/en/met/ag/strat/forschung/SOLARIS/Inputdata

811 Lelieveld J et al (2002) Global air pollution crossroads over the Mediterranean. Science 298: $812 \quad 794-799$

813 Lenton TM et al (2008) Tipping elements in the Earth's climate system. Proc Natl Acad Sci USA $814 \quad 105: 1786-1793$

815 Manabe S, Delworth T (1990) The temporal variability of soil wetness and its impact on climate. 816 Climatic Change 16: 185-192

817 May W (2011) The sensitivity of the Indian summer monsoon to a global warming of $2^{\circ} \mathrm{C}$ with 818 respect to pre-industrial times. Clim Dyn 37 (9-10): 1843-1868

819 Meehl GA, Arblaster JM (2003) Mechanisms for projected future changes in South Asian 820 monsoon precipitation. Clim Dyn 21:659-675

821 Meehl GA, Arblaster JM, Collins WD (2008) Effects of black carbon aerosols on the Indian 822 monsoon. J Clim 21: 2869-2882

823 Mishra V, Smoliak BV, Lettenmaier DP, Wallace JM (2012) A prominent pattern of year-to-year 824 variability in Indian summer monsoon rainfall. Proc Natl Acad Sci USA 109: 7213-7217

825 Pai DS, Sridhar L, Badwaik, MR, Rajeevan M (2014) Analysis of the daily rainfall events over 826 India using a new long period (1901-2010) high resolution $\left(0.25^{\circ}\right.$ x $\left.0.25^{\circ}\right)$ gridded rainfall dataset 827 Clim Dyn doi:10.1007/s00382-014-2307-1

828 Rajeevan M, Bhate J, Jaswal AK (2008) Analysis of variability and trends of extreme rainfall 829 events over India using 104 years of gridded daily rainfall data. Geophys Res Lett 35: L18707, 830 doi:10.1029/2008GL035143 
Rajeevan M, De US, Prasad RK (2000) Decadal variability of sea surface temperature, cloudiness and monsoon depressions in the north Indian Ocean. Curr Sci 79: 283-285

Rajendran K, Kitoh A, Srinivasan J, Mizuta R, Krishnan R (2012) Monsoon circulation interaction with Western Ghats orography under changing climate: Projection by a $20-\mathrm{km}$ mesh AGCM. Theor Appl Climatol 110 (4): 555-571

Ramanathan V. et al. (2005) Atmospheric Brown Clouds: Impacts on South Asian climate and hydrological cycle. Proc Natl Acad Sci USA 102: 5326-533

Ramankutty N et al (2006) Global Land-Cover Change: Recent Progress, Remaining Challenges in Land-Use and Land-Cover Change - Local Processes and Global Impacts, E.F. Lambin, H. Geist, Ed. (Springer, Berlin, Heidelberg, New York), pp. 9-39

Ramarao MVS, Krishnan R, Sanjay J, Sabin TP (2015) Understanding land surface response to changing South Asian monsoon in a warming climate. Earth Syst. Dynam. Discuss. 6: 1-34. www.earth-syst-dynam-discuss.net/6/1/2015/doi:10.5194/esdd-6-1-2015

Ramesh Kumar MR, Krishnan R, Syam S, Unnikrishnan AS, Pai DS (2009) Increasing trend of 'break-monsoon' conditions over India - Role of ocean-atmosphere processes in the Indian Ocean. IEEE Geosci Rem Sens Lett 6: 332-336

Rao BRS, Rao DVB, Rao VB (2004) Decreasing trend in the strength of the Tropical Easterly Jet during the Asian summer monsoon season and the number of tropical cyclonic systems over Bay of Bengal. Geophys Res Lett 31: L14103 doi:101029/2004GL019817

Rayner NA et al (2003) Global analyses of sea surface temperature, sea ice, and night marine air temperature since the late nineteenth century. J Geophys Res 108: D144407, doi: 10.1029/2002JD002670

Rodell M, Velicogna I, Famiglietti JS (2009) Satellite-based estimates of groundwater depletion in India. Nature 460: 999-1003

Roehrig R et al (2013) The present and future of the West African monsoon: A process-oriented assessment of CMIP5 simulations along the AMMA transect. J Clim 26: 6471-6505

Romatschke U, Houze Jr RA (2011) Characteristics of precipitating convective systems in the South Asian monsoon. J Hydrometeor 12: 3-26 
Roxy MK et al (2015) Drying of Indian subcontinent by rapid Indian Ocean warming and a weakening land-sea thermal gradient. Nature Communications 6:7423

Sabade SS, Kulkarni A, Kripalani RH (2011) Projected changes in South Asian summer monsoon by multi-model global warming experiments. Theor Appl Climatol 103 (3-4): 543-565

Sabin TP et al. (2013) High resolution simulation of the South Asian monsoon using a variable resolution global climate model. Clim Dyn 41: 173-194

Sadourny R, Laval K (1984) January and July performance of the LMD general circulation model. New Perspectives in Climate Modelling. Eds. Berger A, Nicolis C Elsevier Science Publishers, Amsterdam, 173-197

Saha A, Ghosh S, Sahana AS, Rao EP (2014) Failure of CMIP5 climate models in simulating post-1950 decreasing trend of Indian monsoon. Geophys Res Lett 41: 7323-7330

Salzmann M, Weser H, Cherian R (2014) Robust response of Asian summer monsoon to anthropogenic aerosols in CMIP5 models. J Geophys Res 119: 11321-11337

Sanap SD, Pandithurai G, Manoj MG (2015) On the response of Indian summer monsoon to aerosol forcing in CMIP5 model simulations. Clim Dyn DOI:10.1007/s00382-015-2516-2

Santer BD et al. (2008) Consistency of modelled and observed temperature trends in the tropical troposphere. Int. J. Climatol 28: 1703-1722

Sathiyamoorthy (2005) Large scale reduction in the size of the Tropical Easterly Jet. Geophys Res Lett 32: L14802 doi:10.1029/2005GL022956

Semazzi FHM, Mehta V, Sud YC (1988) An investigation of the relationship between subSaharan rainfall and global sea surface temperatures. Atmosphere-Ocean 26: 118-138

Seneviratne SI et al (2010) Investigating soil moisture-climate interactions in a changing climate: A review. Earth-Science Reviews 99: 125-161

Sharmila S, Joseph S, Sahai AK, Abhilash S, Chattopadhyay R (2015) Future projection of Indian summer monsoon variability under climate change scenario: An assessment from CMIP5 climate models. Global and Planetary Change 124: 62-78 
Singh D, Tsiang M, Rajaratnam B, Diffenbaugh NS (2014) Observed changes in extreme wet and dry spells during the South Asian summer monsoon season. Nature Climate Change 4: 456461

Sinha A et al (2015) Trends and oscillations in the Indian summer monsoon rainfall over the last two millennia Nature Communications doi:10.1038/ncomms7309

Stano G, Krishnamurti TN, Vijaya Kumar TSV, Chakraborty A (2002) Hydrometeor structure of a composite monsoon depression using the TRMM radar. Tellus 54A: 370-381

Stevens B, Feingold, G (2009) Untangling aerosol effects on clouds and precipitation in a buffered system. Nature 461: 607-613

Swapna P, Krishnan R, Wallace JM (2013) Indian Ocean and monsoon coupled interactions in a warming environment. Clim Dyn 42: 2439-2454

Szopa S et al (2013) Aerosol and ozone changes as forcing for climate evolution between 1850 and 2100. Clim Dyn 40: 2223-2250

Thornthwaite CW (1948) An approach toward a rational classification of climate. Geogr Rev 38: $55-94$

Tiedtke M (1989) A comprehensive mass flux scheme for cumulus parameterization in largescale models. Mon Wea Rev 117: 1179-1800

Toreti A et al (2013) Projections of global changes in precipitation extremes from Coupled Model Intercomparison Project Phase 5 models. Geophys Res Lett doi:10.1002/grl.50940

Turner AG, Annamalai H (2012) Climate Change and the South Asian summer monsoon. Nature Climate Change 2: 587-595

Turner AG, Hannachi A (2010) Is there regime behavior in monsoon convection in the late $20^{\text {th }}$ century? Geophys Res Lett 37: L16706, doi:10.1029/2010GL044159

Turner AG, Slingo JM (2009) Uncertainties in future projections of extreme precipitation in the Indian monsoon region. Atmos Sci Lett 10:152-168

Ueda H, Iwai A, Kuwako K, Hori ME (2006) Impact of anthropogenic forcing on the Asian summer monsoon as simulated by eight GCMs. Geophys Res Lett 33: L06703 doi:10.1029/2005GL025336 
913 Vellore RK, Krishnan R, Pendharkar J, Choudhury AD, Sabin TP (2014) On the anomalous 914 precipitation enhancement over the Himalayan foothills during monsoon breaks. Clim Dyn 915 DOI: $10.1007 / \mathrm{s} 00382-013-2024-1$

916 Vicente-Serrano SM, Begueria S, Lopez-Moreno JI (2010) A multiscalar drought index sensitive 917 to global warming. The Standardized Evapotranspiration Index. J Clim 23: 1696-1718

918 Wang B, Yim S.-Y, Lee J.-Y, Liu J, Ha K.-J (2014) Future change of Asian-Australian monsoon 919 under RCP4.5 anthropogenic warming scenario. Clim Dyn 42: 83-100

920 Willet KM, Jones PD, Gillett NP, Thorne PW (2008) Recent changes in surface humidity: 921 Development of the HadCRUH dataset. J Clim 21: 5364-5383

922 Veechi GA, Soden BJ, Wittenberg AT, Held IM, Leetma A, Harrison MJ (2006) Weakening of 923 tropical Pacific atmospheric circulation due to anthropogenic forcing. Nature 441: 73-76

924 Xie SP, Saji NH, Wang Y (2006) Role of narrow mountains in large-scale organization of Asian 925 monsoon convection J Clim 19: 3420-3429

926 Yatagai A, Kamiguchi K, Arakawa O, Hamada A, Yasutomi N, Kitoh A (2012) APRHODITE: 927 Constructing a long-term daily gridded precipitation dataset for Asia based on a dense network 928 of rain gauges. Bull Amer Meteor Soc 93: 1401-1415

929 Zickfeld K, Knopf B, Petoukhov V, Schellnhuber HJ (2005) Is the Indian summer monsoon 930 stable against global change? Geophys Res Lett 32: L15707 doi:10.1029/ 2005GL022771 


\section{Figure Captions}

\section{Figure 1 | Temporal evolution of the observed and simulated monsoon hydroclimatic} signals. (a) Time-series of 5-year running mean of seasonal (June-September) monsoon precipitation $\left(\mathrm{mm} \mathrm{day}^{-1}\right)$ averaged over land-points in the Indian region $\left(70^{\circ} \mathrm{E}-90^{\circ} \mathrm{E}, 10^{\circ} \mathrm{N}-28^{\circ} \mathrm{N}\right.$; see inset in panel 'b') - based on IMD observations (black line), HIST1 (brown), RCP4.5 (red), HISTNAT1 (blue), CMIP5-Multimodel-Mean (dark grey), IPSL-CM5A-LR (purple) and IPSLCM5A-MR (green). The grey shading is the inter-model spread, ranging between $\mu+\sigma$ and $\mu-\sigma$, where $\mu$ and $\sigma$ are the mean and standard-deviation based on simulations from 21 CMIP5 models (Table.3) (b) Time-series of SPEI averaged over the Indian region (c) Temporal variation in the number of heavy-precipitation events (precipitation intensity $\geq 100 \mathrm{~mm} \mathrm{day}^{-1}$ ) during the JJAS season over the land points of central India $\left(74.5^{\circ} \mathrm{E}-86.5^{\circ} \mathrm{E}, 16.5^{\circ} \mathrm{N}-26.5^{\circ} \mathrm{N}\right.$; see inset). The black, brown, blue and red lines in ' $b$ ' and 'c' are same as described in 'a'. Information on linear-trends and statistical significance for seasonal monsoon precipitation and frequency of heavyprecipitation events are given in Table. 1 and Table. 4 respectively.

Figure 2 | Spatial map of changes in the seasonal monsoon rainfall during (1951-2005) from observations and high-resolution simulations (a) APHRODITE (b) HIST1 (c) HIST2 (d) IPSL-CM5A-LR. The monsoon rainfall changes are computed at each grid-cell using leastsquare linear trends and expressed as $\mathrm{mm} \mathrm{day}^{-1}(55 \text { years })^{-1}$. Only values that exceed the $95 \%$ confidence level, based on a student's t-test, are displayed.

Figure 3 | Time-series of interannual variations in the seasonal monsoon precipitation (mm day $\left.^{-1}\right)$ averaged over land-points of the Indian domain $\left(70^{\circ} \mathrm{E}-9^{\circ} \mathrm{E}, \mathbf{1 0}^{\circ} \mathrm{N}-28^{\circ} \mathrm{N}\right)$. The timeseries is shown for the period 1951-2005 based on IMD observations (black line), HIST1 (brown solid line), HIST2 (brown dashed line), HISTNAT1 (blue solid line) and HISTNAT2 (blue dashed line). Linear least-square trends and their statistical significance are given in Table. 1.

Figure 4 | Temporal variation of LOESS trends in the seasonal monsoon rainfall averaged over the land-points of the Indian region $\left(7^{\circ} \mathrm{E}-90^{\circ} \mathrm{E}, 1^{\circ} \mathrm{N}-28^{\circ} \mathrm{N}\right)$. Using the locally weighted polynomial regression method (LOESS), time-varying trends are estimated for 
standardized rainfall time-series based on mean and standard deviation values for the period 1951-2005. The LOESS trends are shown for IMD observations (black line), CMIP5 ensemble mean (grey solid line), HIST1+RCP4.5 (red solid line), HISTNAT1 (blue line), IPSL-CM5 (green lines). Local standard-deviations, estimated from the trends of the CMIP5 population, are displayed by the grey dashed lines. Contrary to the coarse-resolution CMIP5 and IPSL-CM5 models, note that the (HIST1+RCP4.5) high-resolution exhibits a prominent declining trend starting from 1940s. Also note that the LOESS trends from (HIST1+RCP4.5) clearly lie outside the range of the CMIP5 trends.

Figure 5 | Attributing the monsoon weakening to anthropogenic influence Map showing the difference in June-September mean precipitation $\left(\mathrm{mm} \mathrm{day}^{-1}\right)$ and $850 \mathrm{hPa}$ winds (vectors; $\mathrm{ms}^{-1}$ ) between the HIST1 and HISTNAT1 simulations for the period (1951-2005). Grey dots correspond to mean precipitation differences (HIST1 minus HISTNAT1) which exceed 95\% confidence level based on a two-tailed student's t-test.

\section{Figure 6 | Decomposing the monsoonal response to GHG and regional forcing elements} Composite difference maps of the simulated June-September precipitation $\left(\mathrm{mm} \mathrm{day}^{-1}\right)$ and 850 $\mathrm{hPa}$ winds $\left(\mathrm{ms}^{-1}\right)$ (a) $\delta\left(\mathrm{No} \_\mathrm{GHG}\right)=\mathrm{HIST} 1$ minus HIST1_GHG (b) $\delta(\mathrm{GHG})=$ HIST1_GHG minus HISTNAT1 (c) $\delta\left(\mathrm{GHG}_{-}\right.$Atmos $)=$HIST1 minus HIST1_PIGHG (d) $\delta(\mathrm{GHG}$ _SST) $=$ $\delta(\mathrm{GHG})$ minus $\delta(\mathrm{GHG}$ _Atmos). The composite maps are constructed for the period (19512000) using the decadal time-slices.

Figure 7 | Temporal evolution of regional=forcing elements and simulated response during 1886-2095 (a) Tree-fraction (\%) in green, Crop-fraction (\%) in brown and Planetary albedo in grey (b) Equatorial IOSST anomaly $\left({ }^{\circ} \mathrm{C}\right.$ ) used in HIST1 + RCP4.5 (brown line) and HadISST (1886-2005) (black line). The grey line is the anthropogenic-aerosol radiative forcing $\left(\mathrm{Wm}^{-2}\right)$ at the top-of-atmosphere (TOA) (c) Sea level pressure (hPa) from HadSLP (1886 - 2005) (black line) and simulations (d) Simulated precipitable water $\left(\mathrm{kg} \mathrm{m}^{-2}\right)$ (e) Vertical shear of zonal winds (U200 minus U850) in $\mathrm{ms}^{-1}$ from the LMDZ4 simulations and NCEP reanalysis (f) Simulated soil moisture $(\mathrm{mm})$. The SST anomalies are averaged for the equatorial region $\left(60^{\circ} \mathrm{E}-90^{\circ} \mathrm{E}, 5^{\circ} \mathrm{S}\right.$ $5^{\circ} \mathrm{N}$; see inset in panel ' $\mathrm{b}$ ') and other variables are averaged over the region $\left(70^{\circ} \mathrm{E}-90^{\circ} \mathrm{E}, 10^{\circ} \mathrm{N}\right.$ - 
994

995

996

997

998

999

1000

1001

1002

1003

1004

1005

1006

1007

1008

1009

1010

1011

1012

1013

1014

1015

1016

1017

1018

1019

1020

1021

1022

1023

1024

$28^{\circ} \mathrm{N}$; see inset in panel ' $\mathrm{d}$ '). The brown lines in panels 'c', 'd', 'e', and ' $\mathrm{f}$ ' correspond to the HIST1 + RCP4.5 experiments and the blue line correspond to HISTNAT1.

Figure 8 | Spatial maps of land-use used in the LMDZ4 experiments. (a) Mean tree-fraction (\%) for the period 1951-2000 (b) Same as 'a' except for crop-fraction (\%) (c) Change in treefraction (\%) shown by difference [(1891-1930) minus (1951-2000)] map (d) Same as 'c' except for crop-fraction $(\%)$. Note the larger spatial coverage of tree area over South and Southeast Asia and China during (1891-1930) relative to (1951-2000); while the crop area coverage was less during (1891-1930) relative to (1951-2000).

\section{Figure 9 | Spatial distribution of mean anthropogenic aerosol forcing from the HIST1} experiment during 1951-2005 (a) Anthropogenic aerosol forcing ( $\mathrm{Wm}^{-2}$ ) at the top-ofatmosphere (TOA) (b) Atmospheric absorption $\left(\mathrm{Wm}^{-2}\right)$ due to anthropogenic aerosols [i.e., aerosol-forcing @ TOA minus aerosol-forcing @ Surface]. The mean aerosol forcing is computed for the JJAS season from the HIST1 simulation during the period 1951-2005.

Figure 10 | Tropical Indian Ocean SST warming trend during (1951-2005) (a) Spatial pattern of linear trend of SST $\left({ }^{\circ} \mathrm{C}\right.$ per 55 years) from the IPSL-CM5A-LR simulation (b) Timeseries of equatorial Indian Ocean SST (IOSST in ${ }^{\circ} \mathrm{C}$ ) anomalies averaged over the region $\left(5^{\circ} \mathrm{S}\right.$ $5^{\circ} \mathrm{N}, 60^{\circ} \mathrm{E}-90^{\circ} \mathrm{E}$ ) from HadISST (black line), IPSL-CM5A-LR (green line), IPSL-CM5A-MR (purple), ensemble mean of CMIP5 models (red line). The grey shading shows the spread of SST anomalies simulated across the CMIP5 models (c) Time-series of IOSST $\delta \mathrm{GM}$ anomalies $\left({ }^{\circ} \mathrm{C}\right)$ $($ IOSST $\delta \mathrm{GM}=$ EQIOSST minus Global Mean SST) for HadISST (black line), IPSL-CM5A-LR (green line). The rapid warming of IOSSTSGM is apparently linked to weakening of the summer-monsoon cross-equatorial flow in recent decades (Swapna et al. 2014).

Figure 11 | Attributing changes in moderate and heavy precipitation types to global and regional forcing. Box-whisker plot of distributions of yearly count of moderate $\left(5 \mathrm{~mm} \mathrm{day}^{-1} \leq\right.$ precipitation intensity $<100 \mathrm{~mm} \mathrm{day}^{-1}$ ) and heavy (precipitation intensity $\geq 100 \mathrm{~mm} \mathrm{day}^{-1}$ ) events over Central India $\left(74.5^{\circ} \mathrm{E}-86.5^{\circ} \mathrm{E}, 16.5^{\circ} \mathrm{N}-26.5^{\circ} \mathrm{N}\right)$ during the period $(1951-2000)$ from HIST1 and HIST1_GHG, expressed as percentage departure relative to HISTNAT1. Note that, 
1025 for each year the events are counted over 750 grid-cells in the Central India domain and 122 days

1026 of the JJAS season. Year-wise departures in frequency counts are first calculated for both 1027 precipitation categories relative to HISTNAT1. The quartiles are then computed from year-wise 1028 counts for the two precipitation categories in HIST1 and HIST1_GHG. Note that HIST1 displays 1029 an opposite change for the moderate (-) and heavy (+) precipitation categories, but HIST1_GHG 1030 shows positive changes for both categories. For changes in the heavy-precipitation category, the 1031 third quartile in HIST1 is significantly higher by $10 \%$ as compared to HIST1_GHG, thus 1032 highlighting the influence of regional forcing on amplifying precipitation extremes.

Figure 12 | Latitude-pressure sections showing difference maps of meridional overturning anomalies. Streamlines are constructed using meridional wind ( $\mathrm{v}$ in $\mathrm{ms}^{-1}$ ) and vertical velocity $\left(\omega \times 150 \mathrm{hPa} \mathrm{s}^{-1}\right)$ averaged over the $70 \mathrm{E}^{\circ}-90^{\circ} \mathrm{E}$ longitudinal band. The anomalies of $\omega$ shaded, such that negative (positive) values correspond to anomalous upward (downward) motions (a) HIST1 (1951 - 2005) minus HISTNAT1 (1951-2005)

(b) RCP4.5 (2006-2050) - HIST1 (1951 $1039-2005)$.

Auxiliary Figure A1 | Time-series of year-wise count of heavy rainfall events (intensity $\geq$ $\left.100 \mathrm{~mm} \mathrm{day}{ }^{-1}\right)$ over Central India $\left(7_{4.5}^{\circ} \mathrm{E}-8_{6.5}^{\circ} \mathrm{E}, 16.5^{\circ} \mathrm{N}-26.5^{\circ} \mathrm{N}\right)$. The counts are for the June-September monsoon season from 1951-2005 based on IMD observations (black line), HIST1 (brown solid line), HIST2 (brown dashed line), HISTNAT1 (blue solid line) and HISTNAT2 (blue dashed line). The linear least-square trends and their statistical significance are

Auxiliary Figure A2 | Difference maps of precipitation (mm day ${ }^{-1}$, shaded) and 850 hPa winds (ms-1, vectors) (a) RCP4.5 minus HISTNAT1 (b) RCP4.5 minus HIST1. The mean of RCP4.5 is for the period 2006-2060. For HIST1 and HISTNAT1, the means are for the period 1951-2005. Note the persistence of weak SAM circulation and rainfall anomalies in the RCP4.5 projection.

1053 
1056

1057

1058

1059

1060

1061

1062

1063

1064

1065

1066

1067

1068

1069

1070

1071

1072

1073

1074

1075

1076

1077

1078

1079

1080

1081

1082

1083

1084

1085

1086

tropospheric circulation (vectors: $\mathrm{ms}^{-1}$ ) between HIST1 and HISTNAT1 for the period (19512005). The temperature and wind fields are vertically averaged between 600 and $200 \mathrm{hPa}$. Note that the TT response over the near-equatorial areas is warmer as compared to that of the extratropics (poleward of $30^{\circ} \mathrm{N}$ ). The cyclonic circulation anomaly over West-Central Asia is associated with cold air advection and subsidence over the Indian subcontinent. The anticyclonic circulation anomaly over the Indian region indicates weakening of the SAM circulation.

\section{Auxiliary Figure A4 | Climatological mean monsoon rainfall and $850 \mathrm{hPa}$ winds from} observations/reanalysis, LMDZ4 high-resolution simulations, IPSL-CM5A models. a, GPCP and NCEP b, HIST1 c, HIST2 d, IPSL-CM5A-MR e, IPSL-CM5A-LR. The means are for the period 1951-2005, except for GPCP rainfall which is for the period 1979-2009. Notice the severe underestimation of monsoon winds and precipitation, particularly over the Western Ghats in the IPSL-CM5A models.

\section{Auxiliary Figure A5 | Coupled variability of monsoon precipitation and low-level winds in} observations and simulations. The first empirical orthogonal function (EOF1) of JJAS precipitation over western Ghats and west-central peninsular India for the period 1941-2005 from (a) Observations (b) HIST1 (c) IPSL-CM5-LR (d, e, f) corresponding principal component (PC1) time-series $(\mathbf{g}, \mathbf{h}, \mathbf{i})$ Pattern obtained by regressing the $850 \mathrm{hPa}$ winds over the Arabian Sea upon the PC1 time-series of rainfall. Note the decreasing trend of PC1 time-series in observations and HIST1 high-resolution simulation, but not in the IPSL-CM5-LR model. Consistent with the decreasing trend of PC1, the regression pattern of westerly winds indicate weakening of the monsoon flow in NCEP reanalysis and HIST1. In contrast, note that the wind variations in the IPSL-CM5-LR are anti-correlated with the increasing trend of PC1 time-series as seen from the easterly anomaly.

\section{Auxiliary Figure A6 | Spatial map of projected future changes in the seasonal monsoon} rainfall. Least-square linear trend of June-September monsoon rainfall from the RCP4.5 simulation expressed as mm day ${ }^{-1}$ (45 years) ${ }^{-1}$ (a) $(2006$ - 2050) (b) (2051 - 2095). Only values exceeding the $95 \%$ confidence level are displayed. 
a CMIP5-ensmean a IPSL-CM5A-MR a IPSL-CM5A-LR
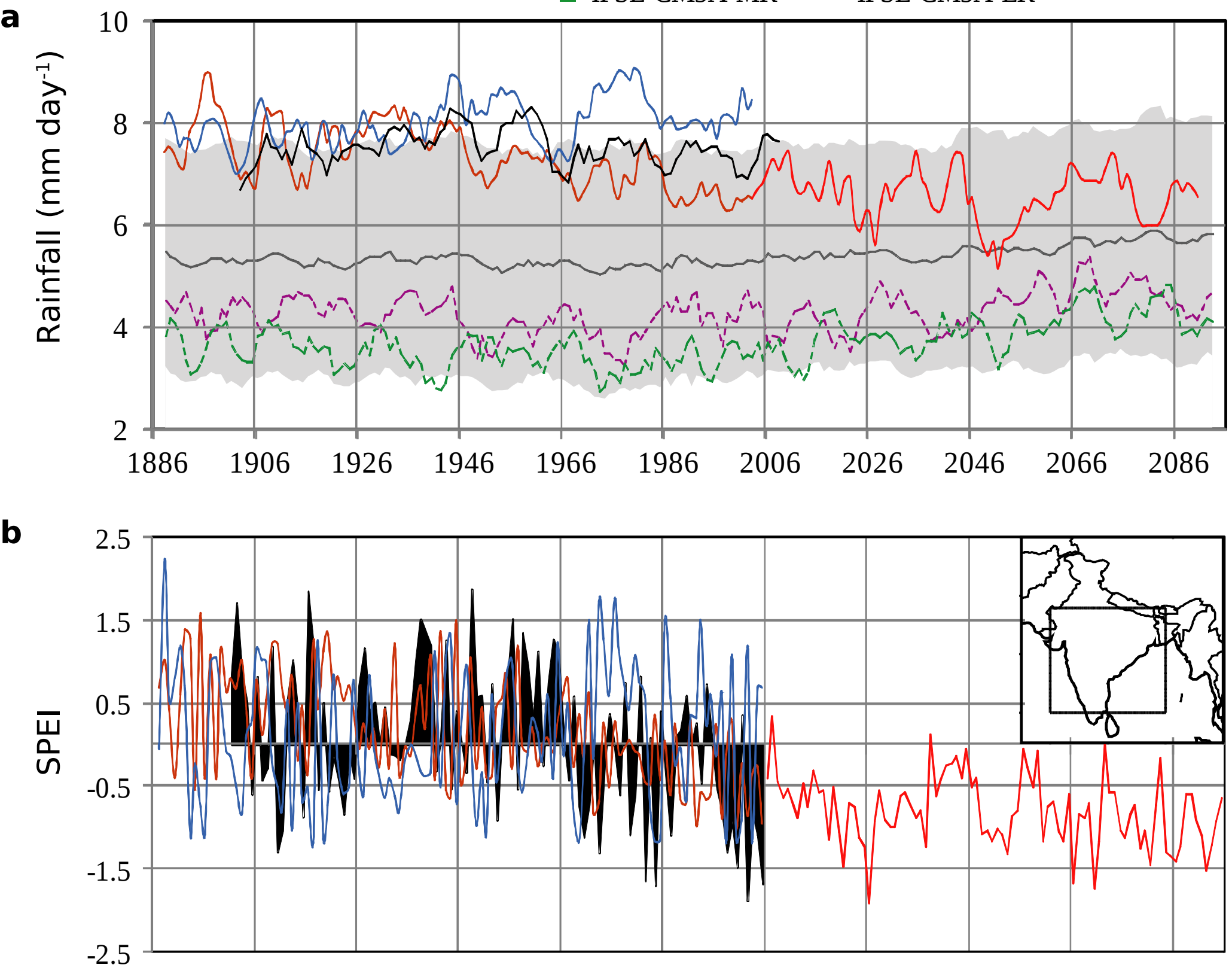

$\begin{array}{lllllllllll}1886 & 1906 & 1926 & 1946 & 1966 & 1986 & 2006 & 2026 & 2046 & 2066 & 2086\end{array}$
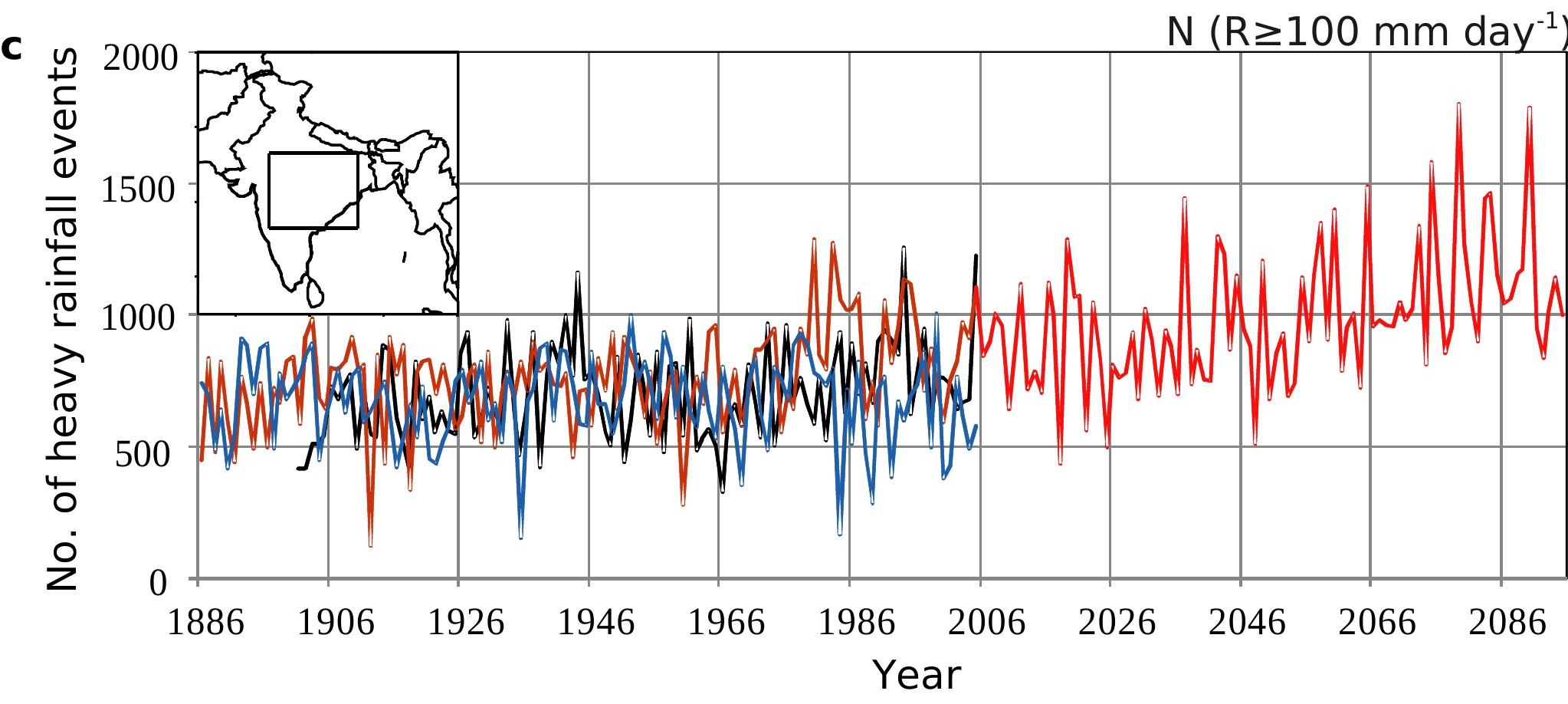


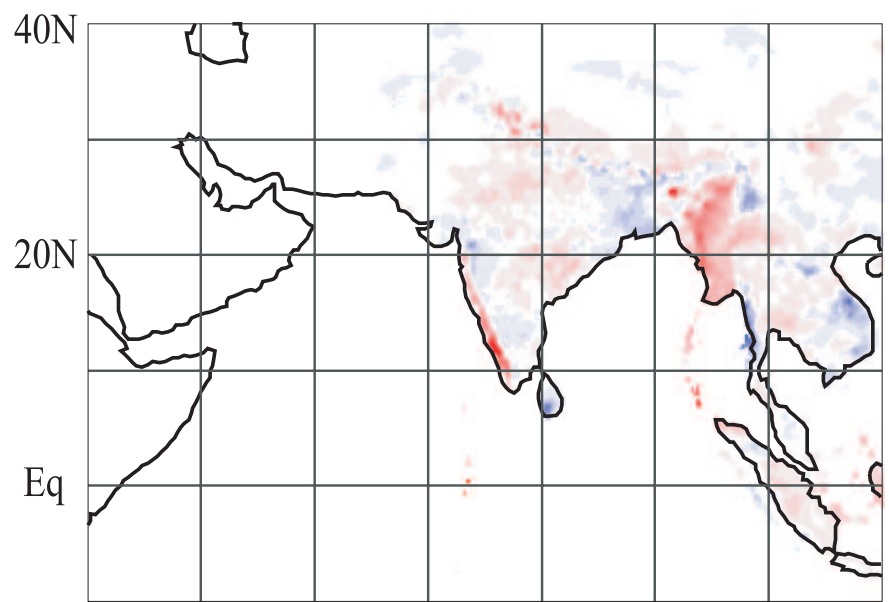

b

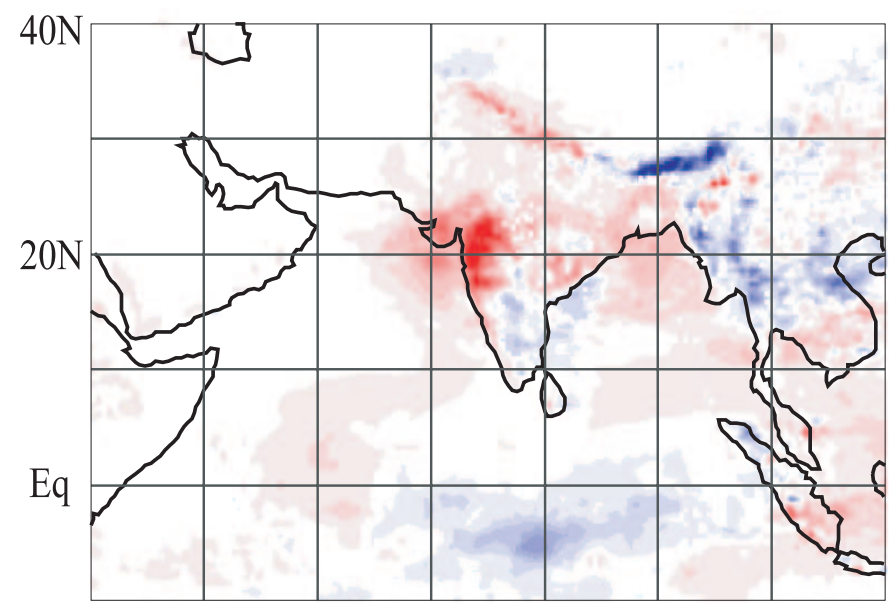

C

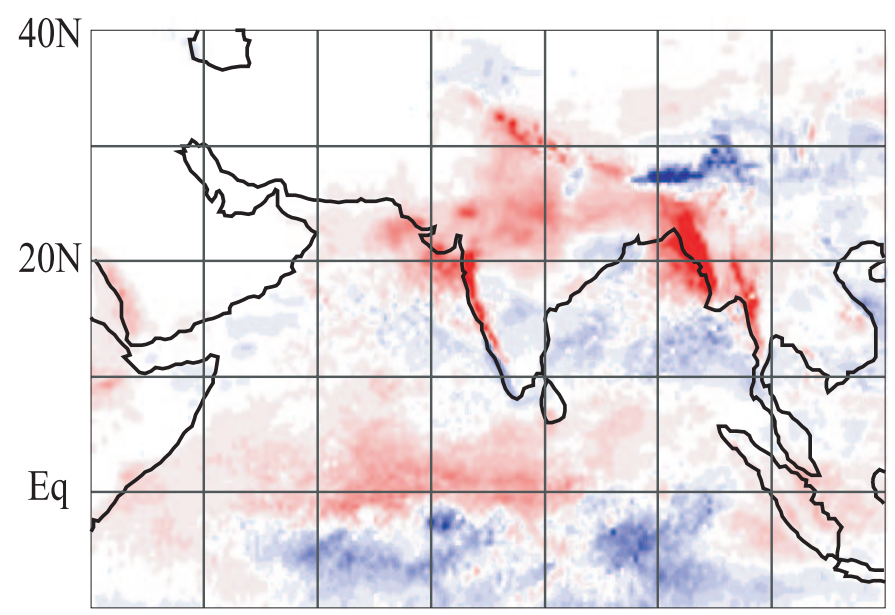

d

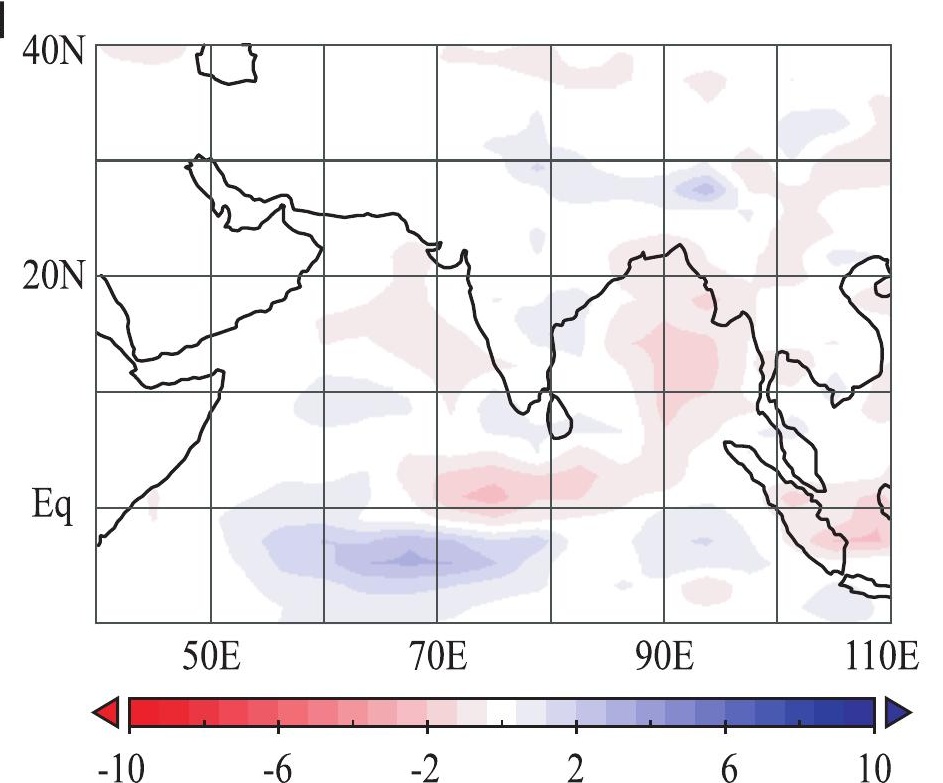


Figure 3

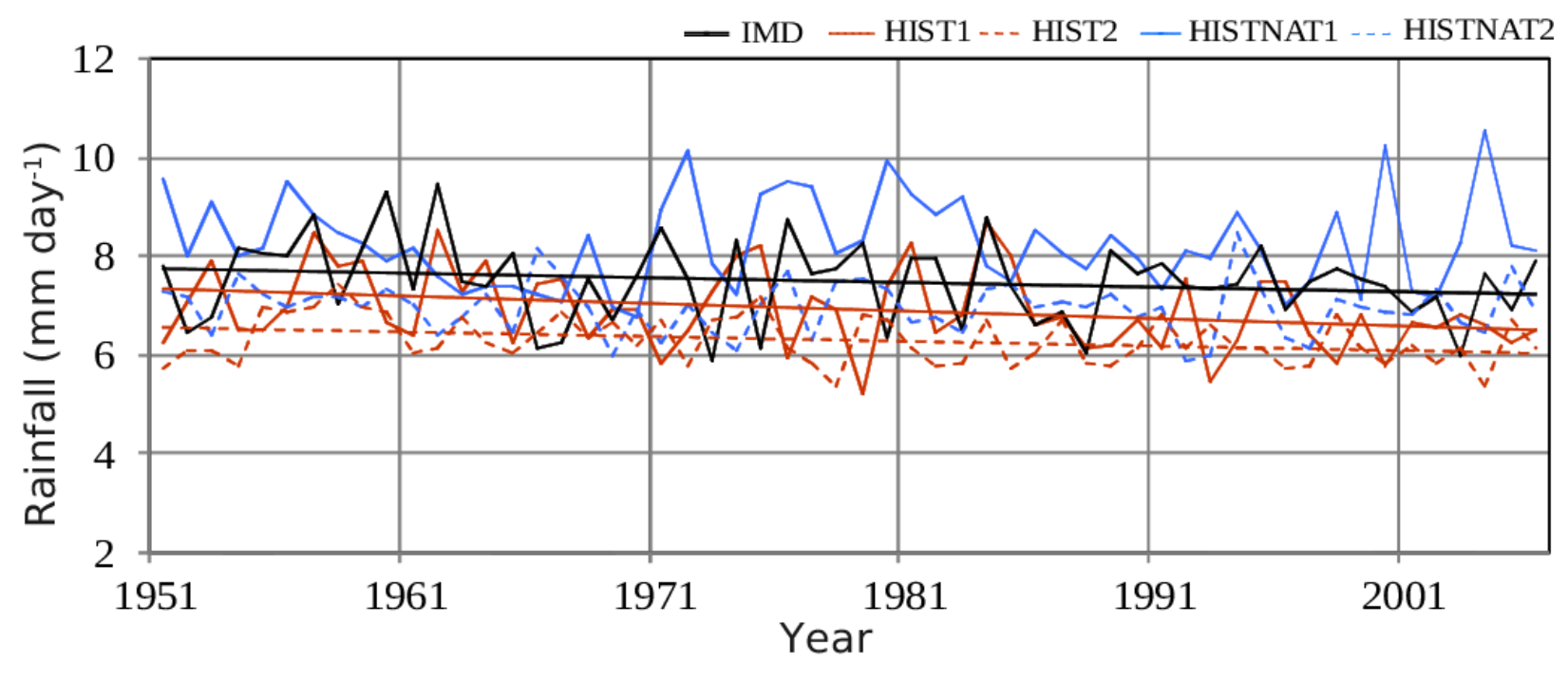




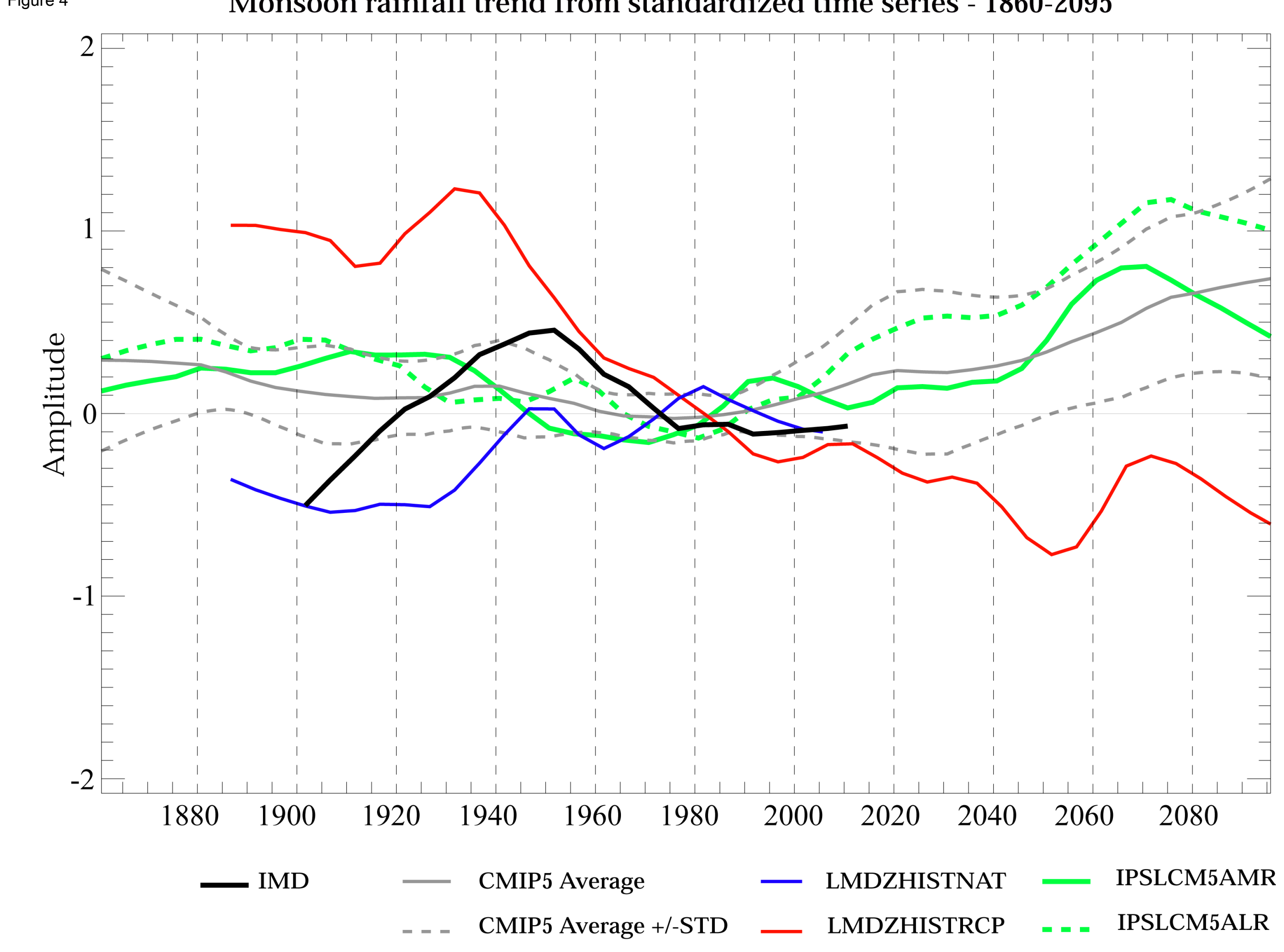


a) $\boldsymbol{\delta}$ (No_GHG)

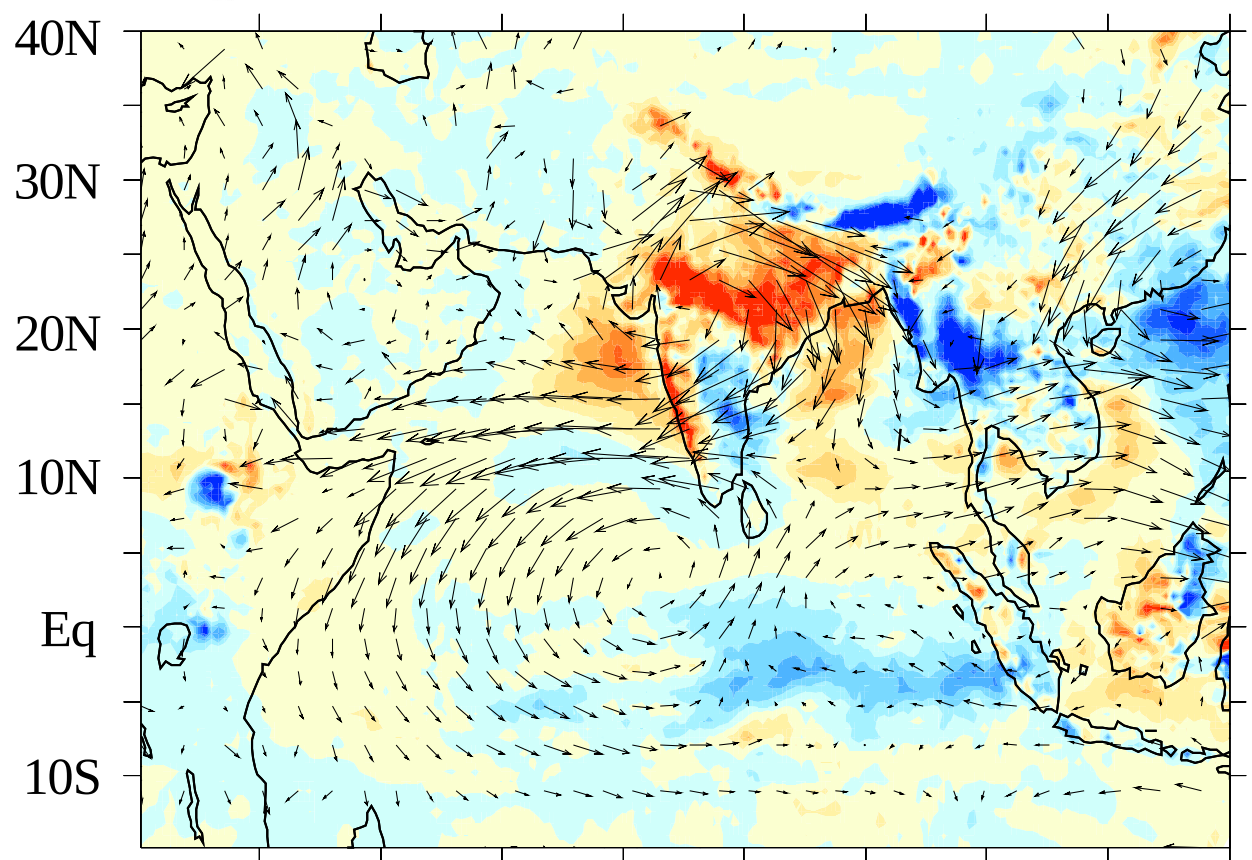

c) $\delta$ (GHG_Atmos)

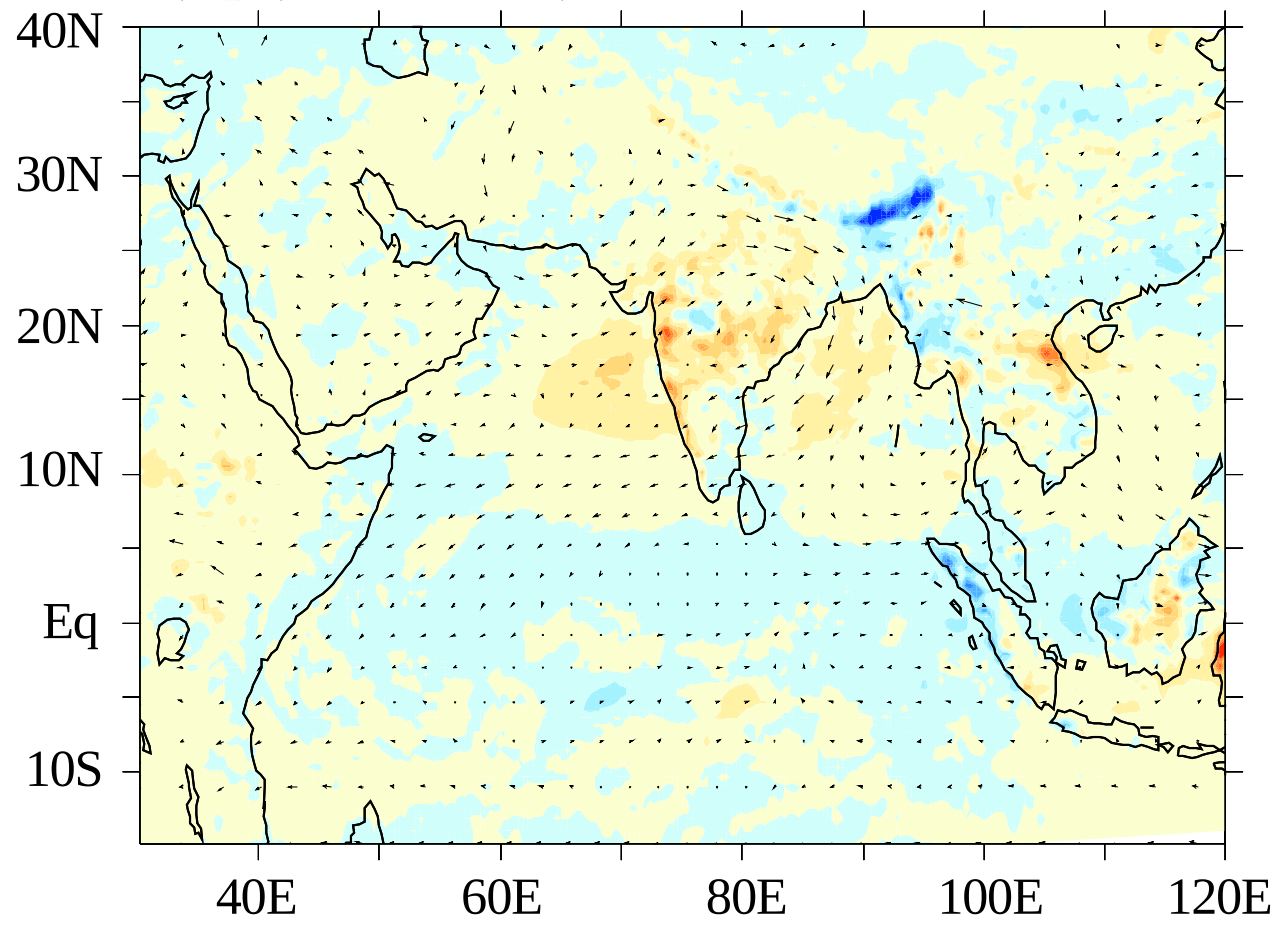

b) $\delta$ (GHG)

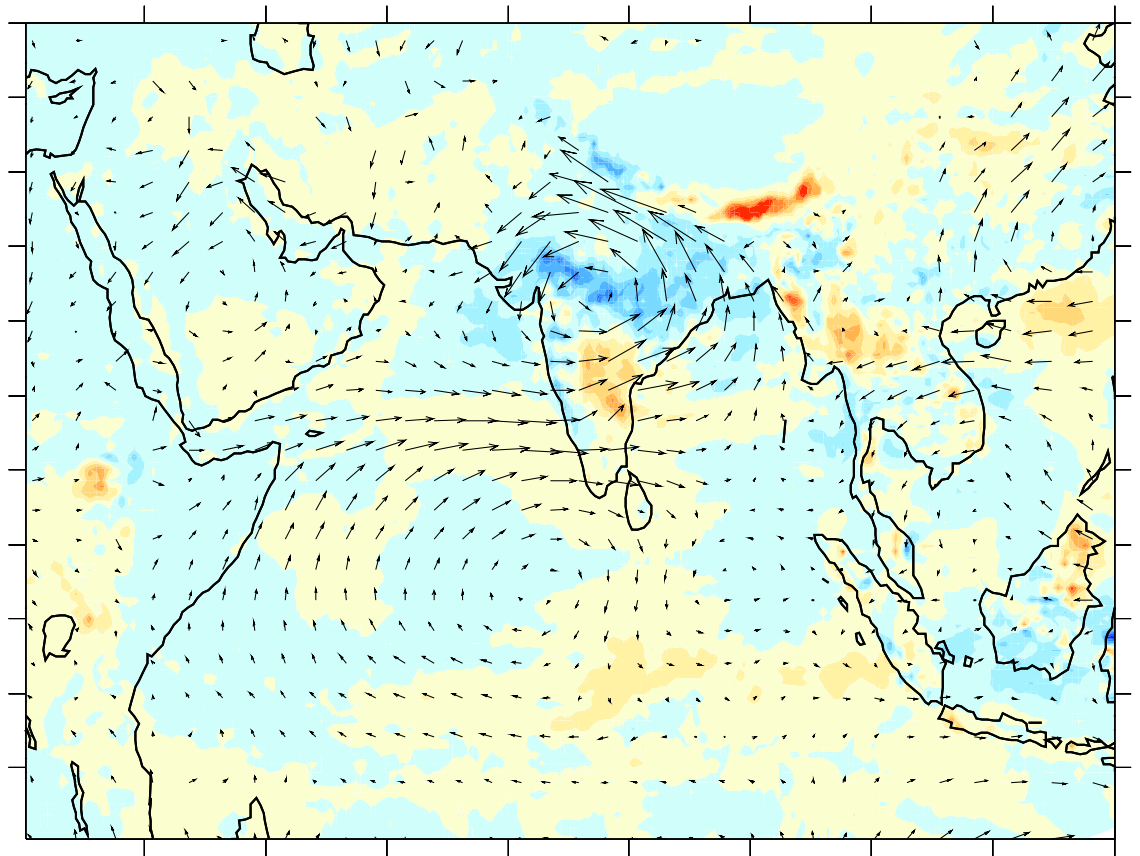

d) $\boldsymbol{\delta}$ (GHG_SST)

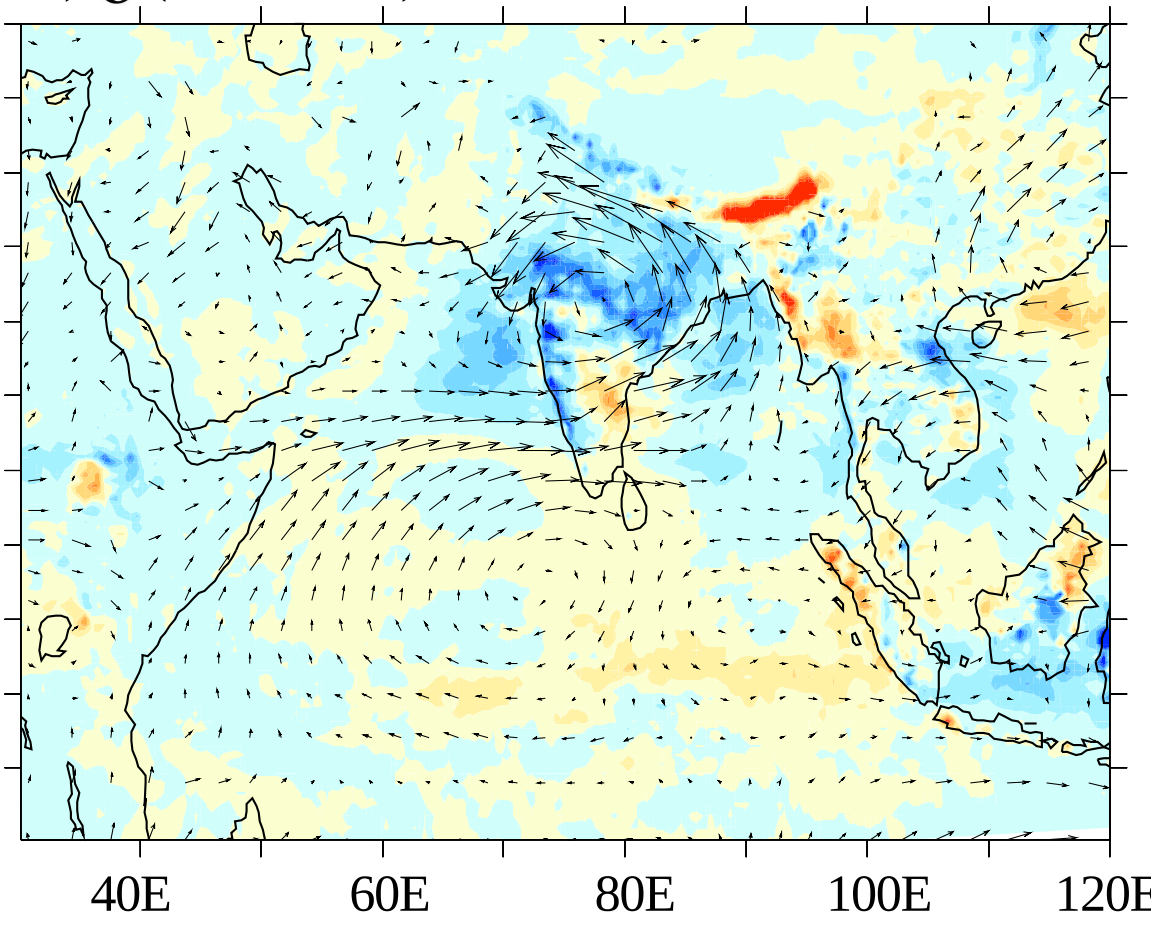

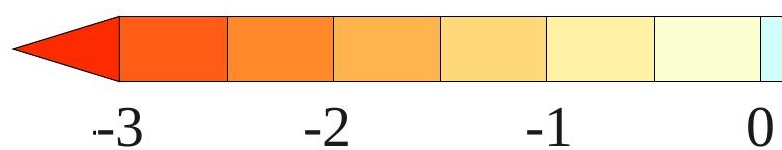

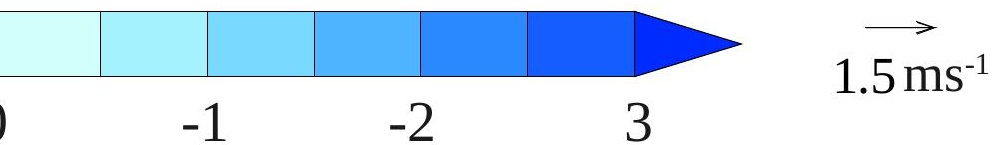




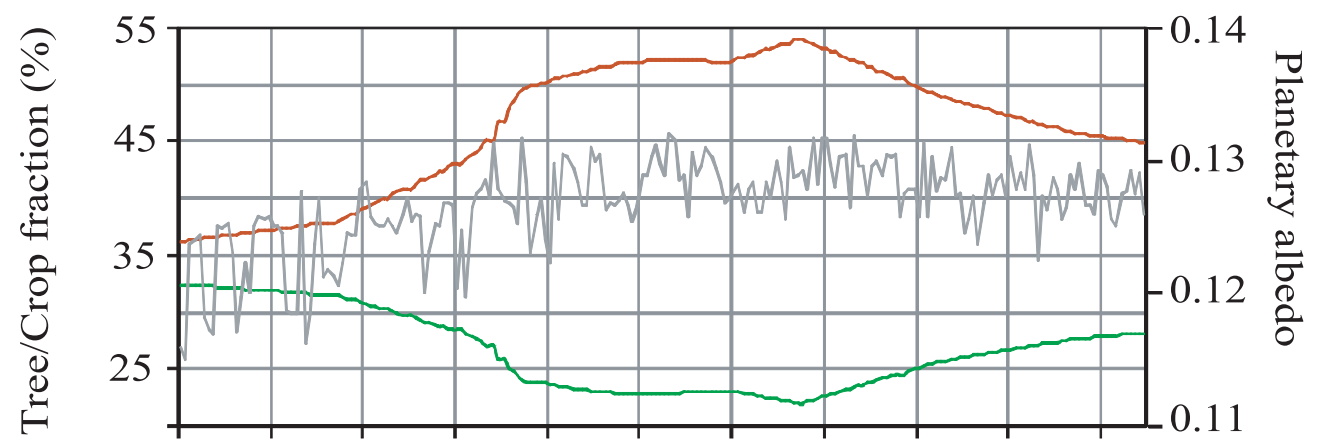

b

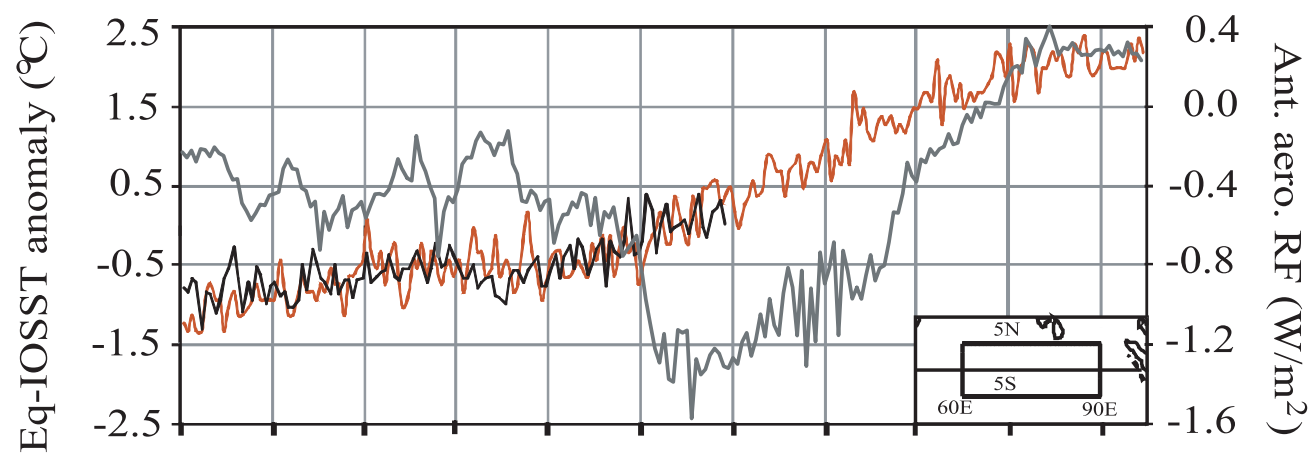

C

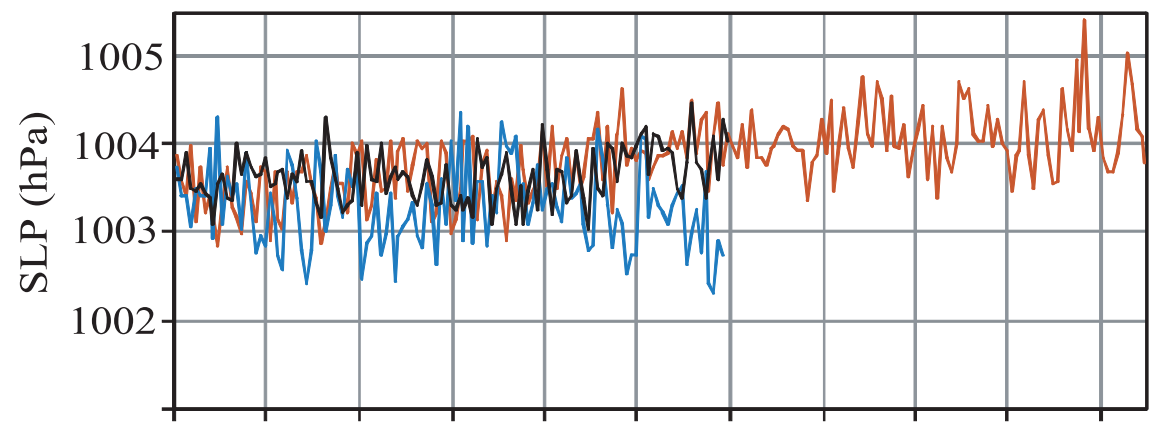

d

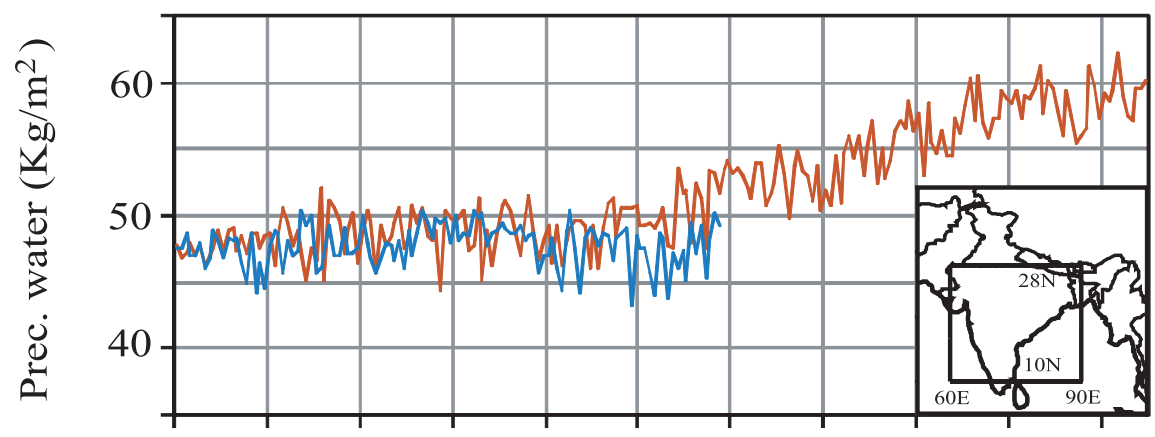

e

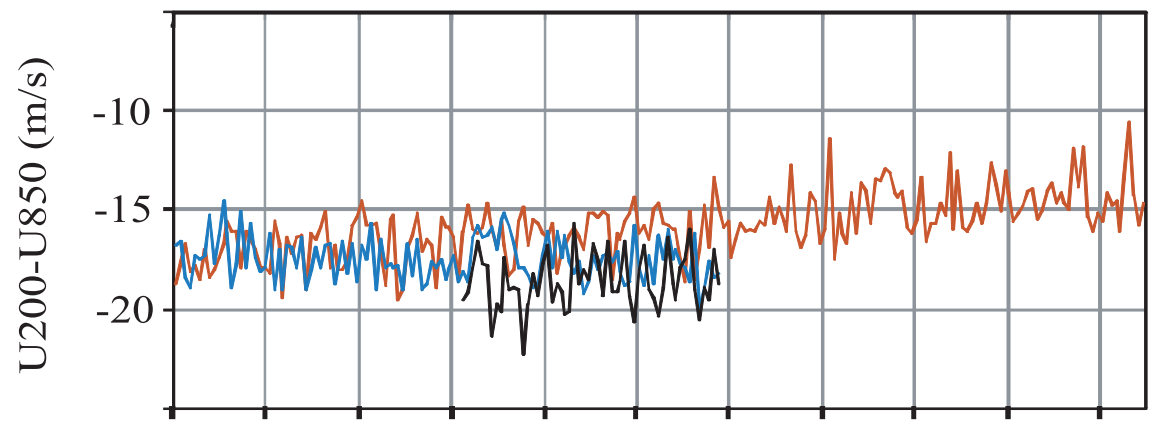

f

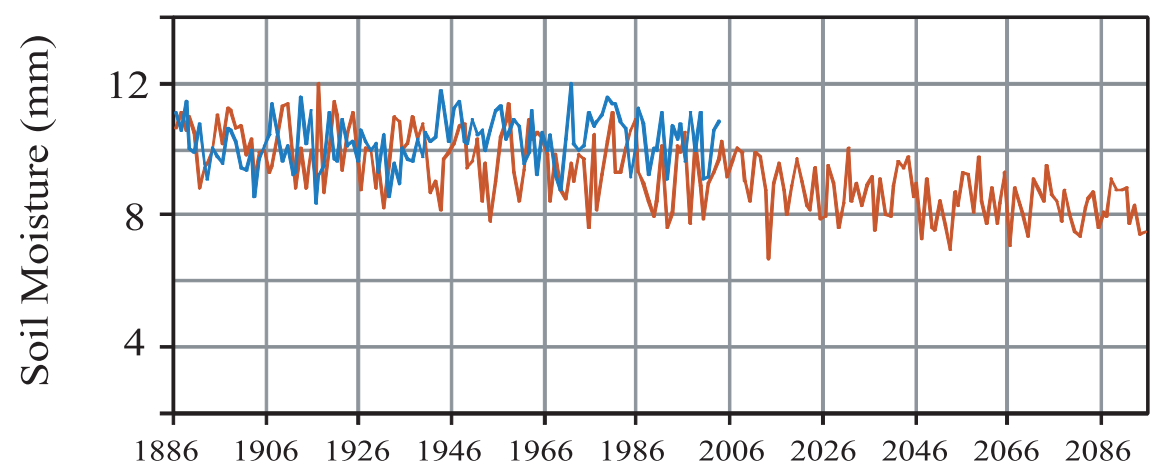


Figure 8
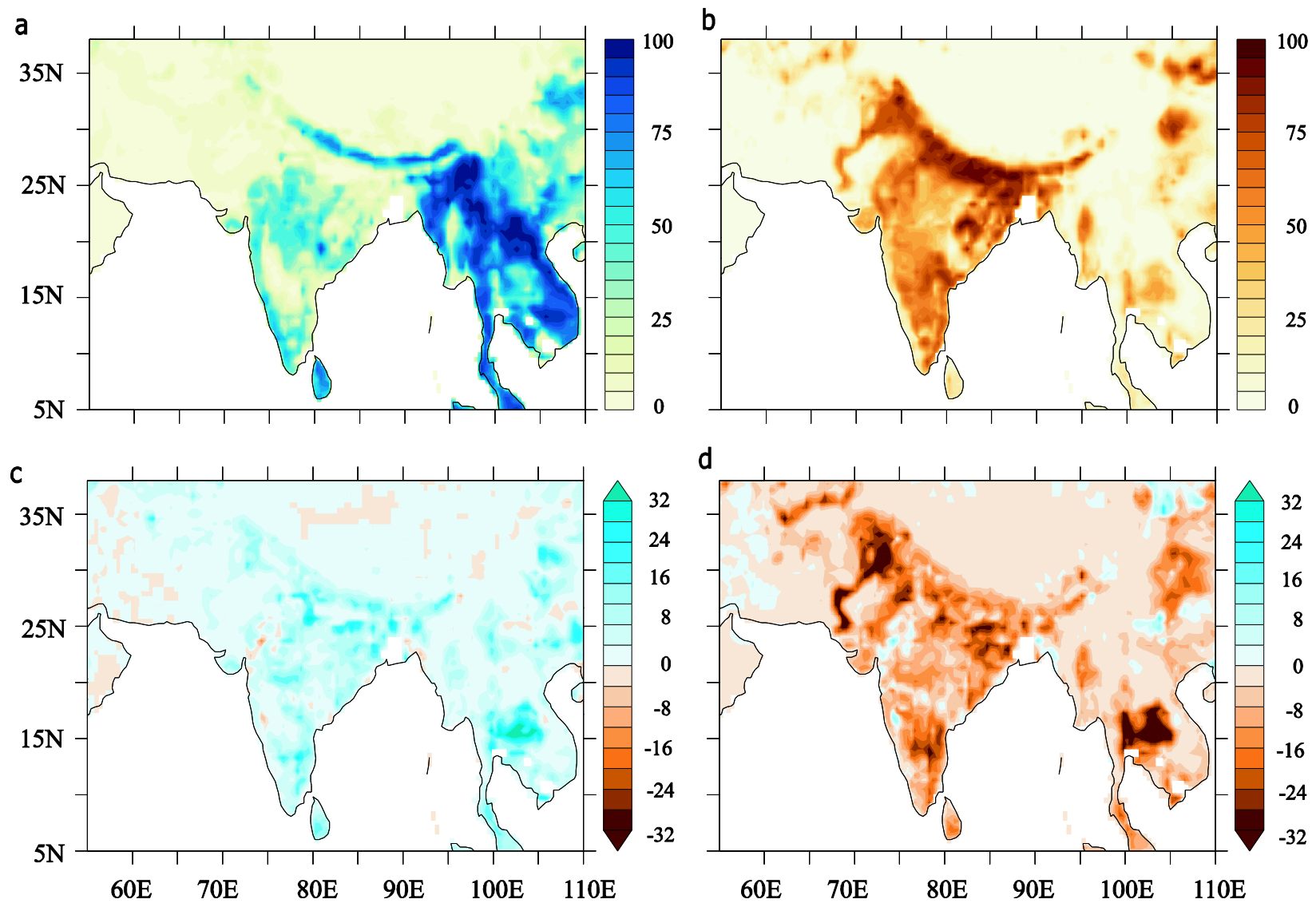
a

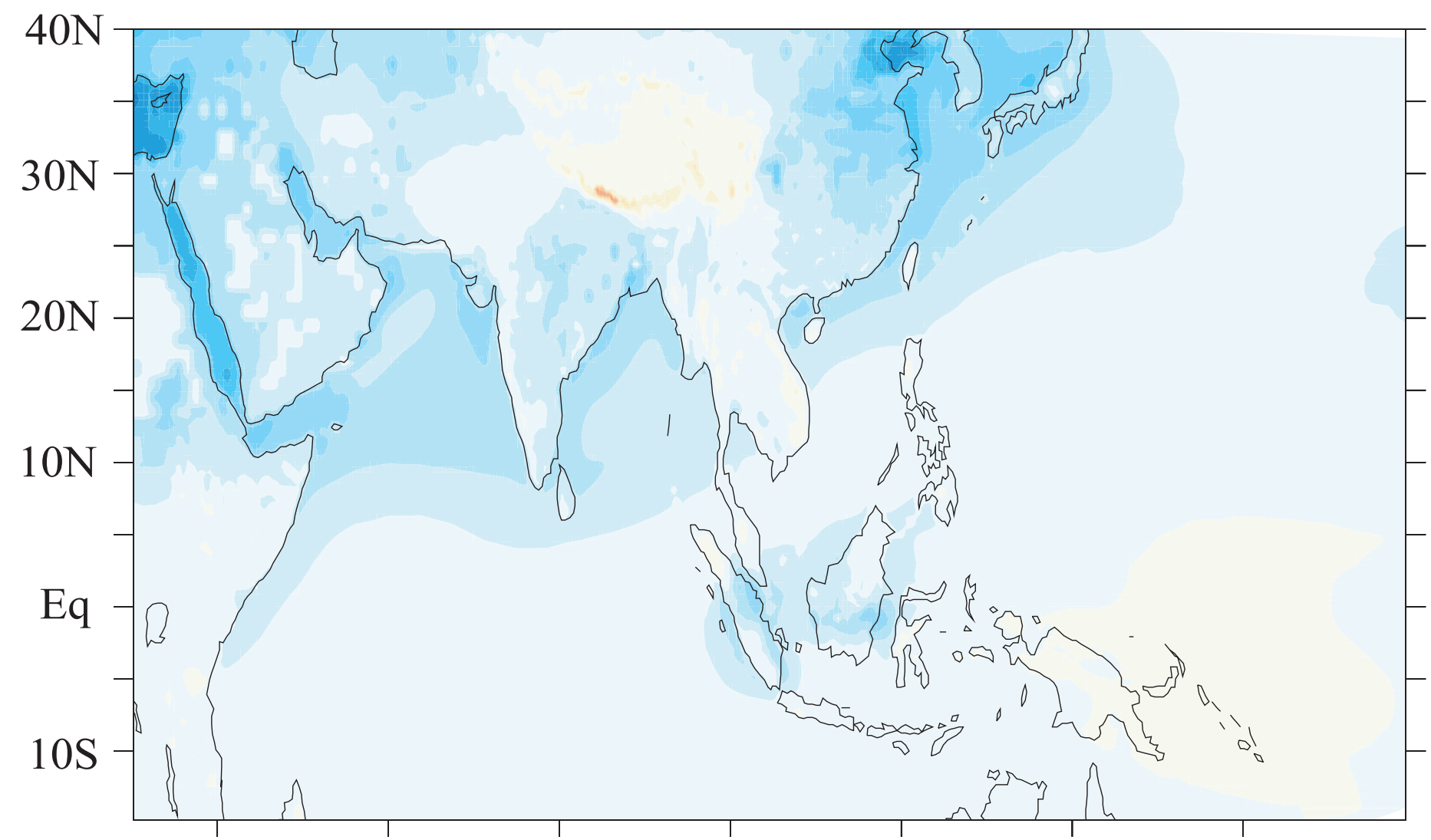

b

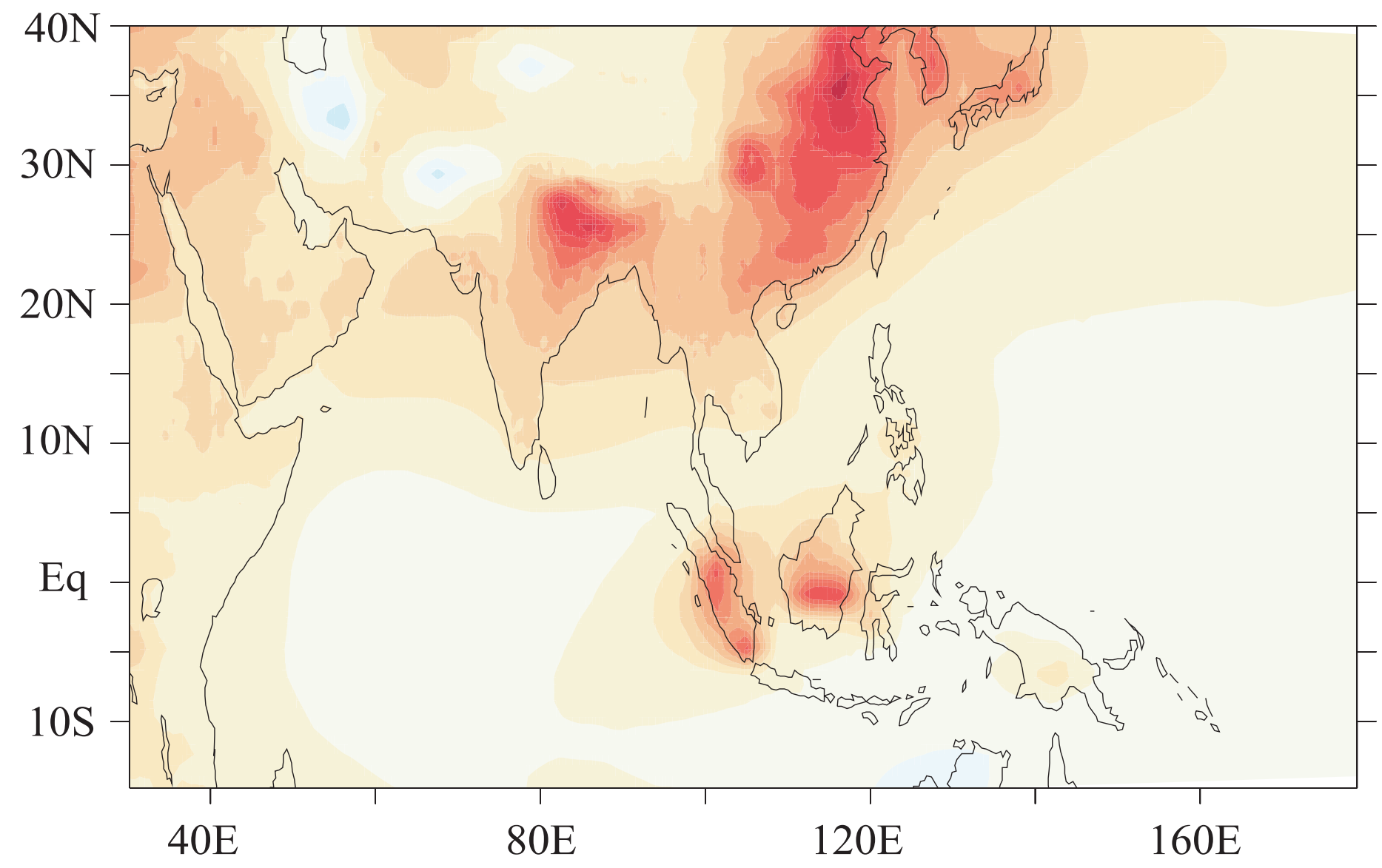

6

4

2

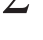

0
-2

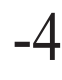

$-6$ 


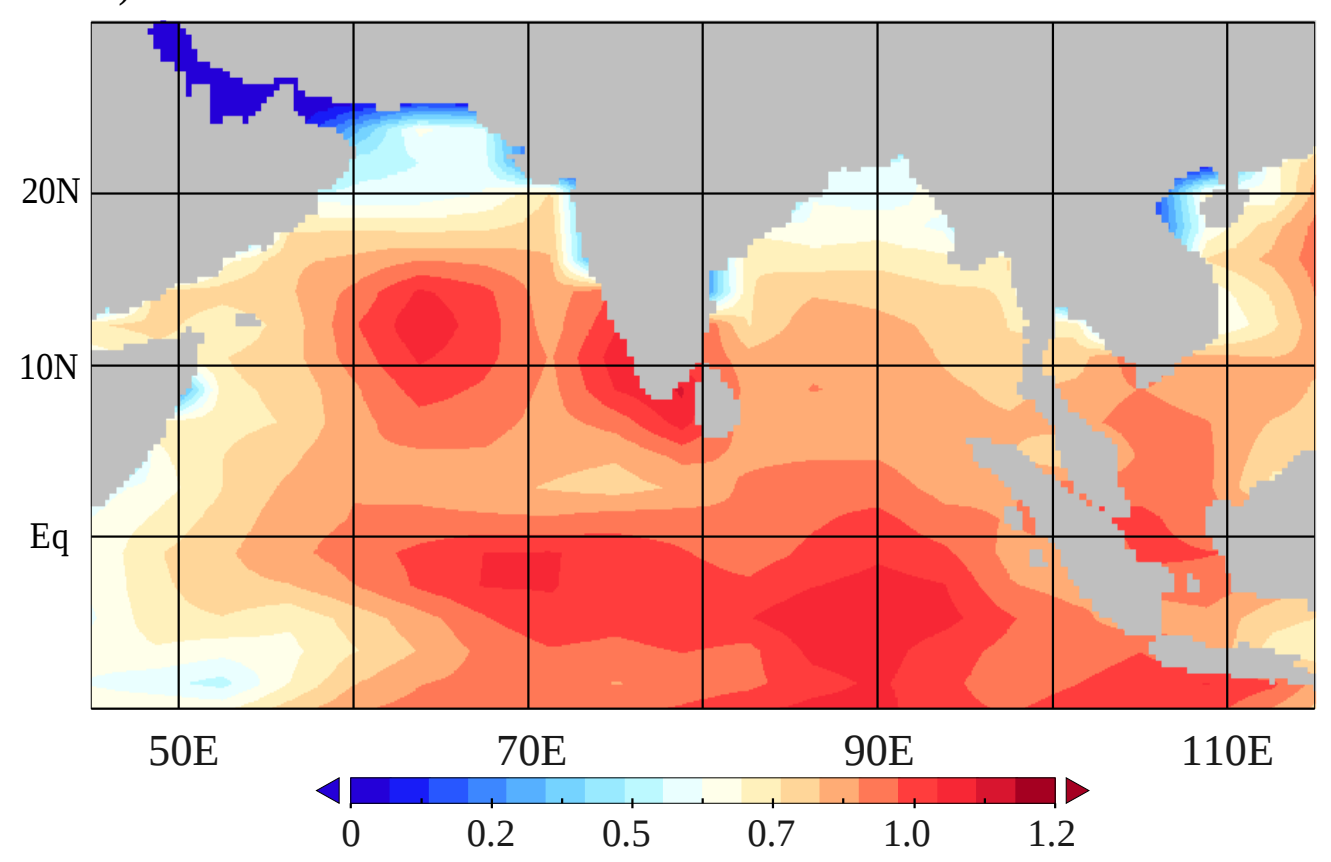

b)

— HadISST — Ensemble mean $\quad$... IPSL-LR $=$ = IPSL-MR
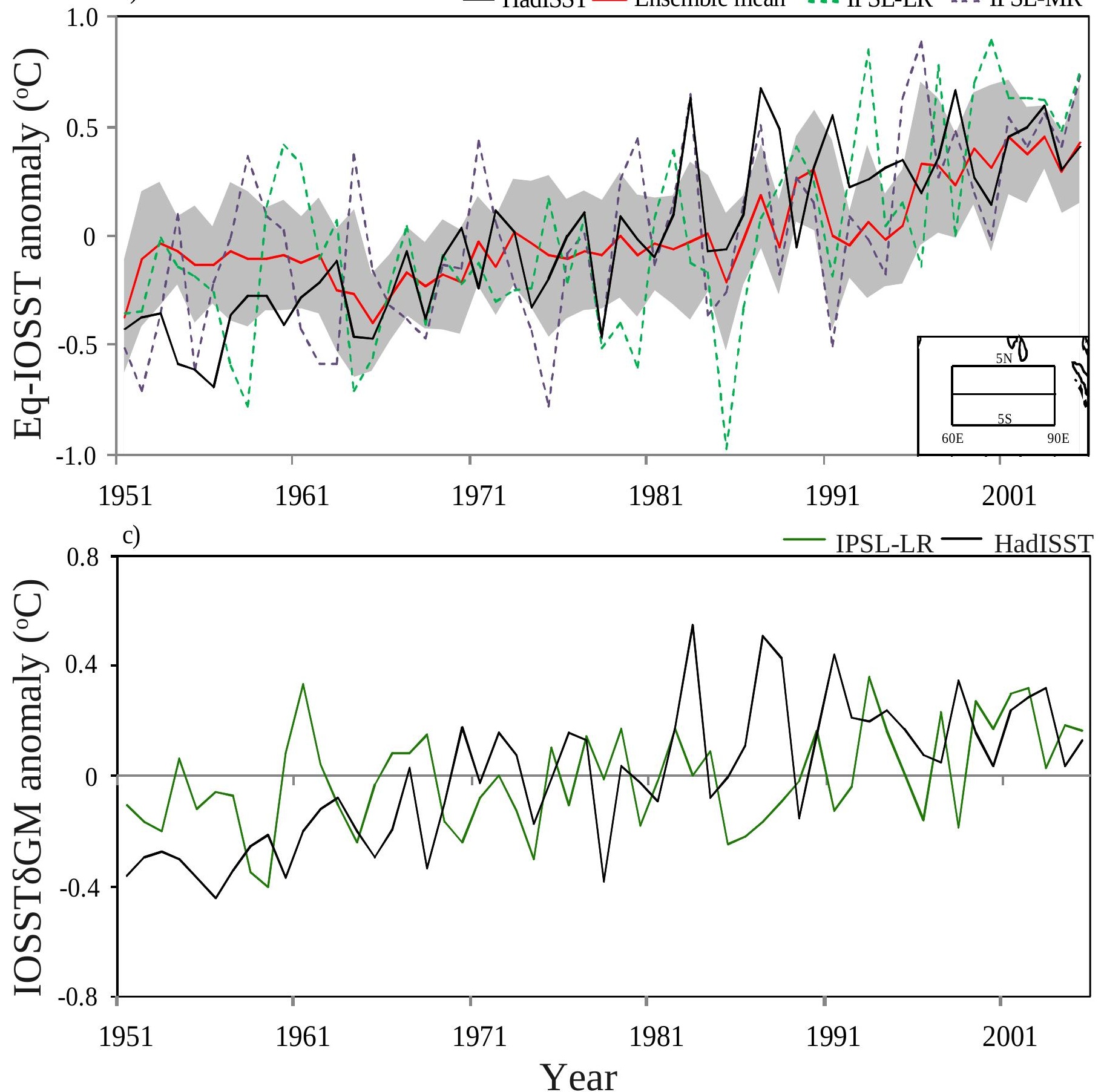


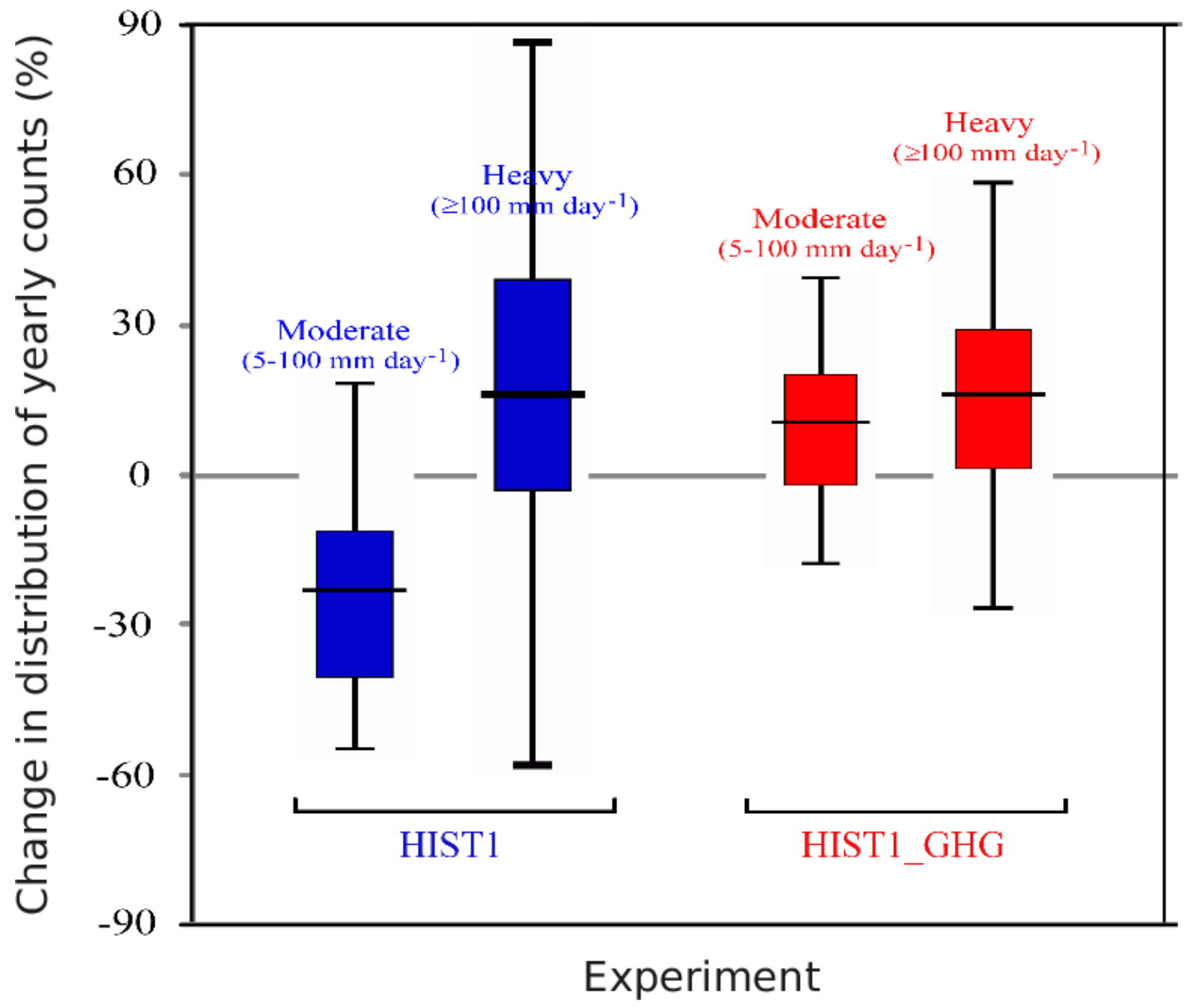


Table.1. Summary of trends of JJAS rainfall averaged over the land points for the Indian region $\left(70-90^{\circ} \mathrm{E}, 10-28^{\circ} \mathrm{N}\right)$. A 5-year running mean has been applied on the rainfall time-series.

\begin{tabular}{|c|c|c|c|c|}
\hline & Rainfall trend & $\begin{array}{l}\text { Mean rainfall } \\
\left(\mathrm{mm} \mathrm{day}^{-1}\right)\end{array}$ & $\begin{array}{l}\% \text { change w.r.t } \\
\text { mean rainfall }\end{array}$ & $\begin{array}{c}\text { P value based on } \\
\text { two tailed } \\
\text { student's t-test }\end{array}$ \\
\hline $\begin{array}{l}\text { IMD dataset } \\
(1951-2005)\end{array}$ & $\begin{array}{c}-0.55 \text { units } \\
\mathrm{mm} \mathrm{day}^{-1}(55 \text { years })^{-1}\end{array}$ & 7.5 & $-7 \%$ & $\mathrm{P}<0.01$ \\
\hline $\begin{array}{c}\text { HIST1 } \\
(1951-2005)\end{array}$ & $\begin{array}{c}-1.1 \text { units } \\
\mathrm{mm} \mathrm{day}^{-1}(55 \text { years })^{-1}\end{array}$ & 6.9 & $-16 \%$ & $\mathrm{P}<0.01$ \\
\hline $\begin{array}{c}\text { HIST2 } \\
(1951-2005)\end{array}$ & $\begin{array}{c}-0.55 \text { units } \\
\mathrm{mm} \mathrm{day}^{-1}(55 \text { years })^{-1}\end{array}$ & 6.3 & $-9 \%$ & $\mathrm{P}<0.01$ \\
\hline $\begin{array}{l}\text { HISTNAT1 } \\
(1951-2005)\end{array}$ & $\begin{array}{c}-0.03 \text { units } \\
\mathrm{mm} \mathrm{day}^{-1}(55 \text { years })^{-1}\end{array}$ & 8.3 & $-0.3 \%$ & $\begin{array}{l}\mathrm{P}=0.54 \text { (not } \\
\text { significant) }\end{array}$ \\
\hline $\begin{array}{l}\text { HISTNAT2 } \\
(1951-2005)\end{array}$ & $\begin{array}{c}\text { - } 0.1 \text { units } \\
\mathrm{mm} \mathrm{day}^{-1}(55 \text { years })^{-1}\end{array}$ & 6.9 & $-1 \%$ & $\begin{array}{l}\mathrm{P}=0.2 \quad \text { (not } \\
\text { significant) }\end{array}$ \\
\hline $\begin{array}{c}\text { RCP4.5 } \\
(2006-2060)\end{array}$ & $\begin{array}{c}-1.1 \text { units } \\
\mathrm{mm} \mathrm{day}^{-1}(55 \text { years })^{-1}\end{array}$ & 6.6 & $-17 \%$ & $\mathrm{P}<0.01$ \\
\hline $\begin{array}{c}\text { RCP4.5 } \\
(2006-2095)\end{array}$ & $\begin{array}{c}-0.29 \text { units } \\
\mathrm{mm} \mathrm{day}^{-1}(90 \text { years })^{-1}\end{array}$ & 6.6 & $-5 \%$ & $\mathrm{P}<0.01$ \\
\hline
\end{tabular}


Table.2. Summary of the LMDZ4 experimental design

\begin{tabular}{|c|c|c|c|c|}
\hline Expt. & Period & Forcing & $\begin{array}{c}\text { Cumulus } \\
\text { convection }\end{array}$ & SST forcing \\
\hline HIST1 & $\begin{array}{c}\text { Historical: } \\
(1886-2005)\end{array}$ & $\begin{array}{l}\text { Natural and } \\
\text { Anthropogenic } \\
\text { forcings }\end{array}$ & Emanuel & $\begin{array}{c}\text { SST_ANOM_IPSL_CM5A_HIST } \\
+ \\
\text { SST_AMIP_CLIM }\end{array}$ \\
\hline HISTNAT1 & $\begin{array}{c}\text { Historical: } \\
(1886-2005)\end{array}$ & Natural only & Emanuel & $\begin{array}{c}\text { SST_ANOM_IPSL_CM5A_HISTNAT } \\
+ \\
\text { SST_AMIP_CLIM }\end{array}$ \\
\hline HIST2 & $\begin{array}{c}\text { Historical: } \\
(1950-2005)\end{array}$ & $\begin{array}{l}\text { Natural and } \\
\text { Anthropogenic } \\
\text { forcings }\end{array}$ & Tiedtke & $\begin{array}{c}\text { SST_ANOM_IPSL_CM5A_HIST } \\
+ \\
\text { SST_AMIP_CLIM }\end{array}$ \\
\hline HISTNAT2 & $\begin{array}{c}\text { Historical: } \\
(1950-2005)\end{array}$ & Natural only & Tiedtke & $\begin{array}{c}\text { SST_ANOM_IPSL_CM5A_HISTNAT } \\
+ \\
\text { SST_AMIP_CLIM }\end{array}$ \\
\hline RCP4.5 & $\begin{array}{l}\text { Future RCP4.5 } \\
\text { scenario }(2006 \\
-2095)\end{array}$ & $\begin{array}{l}\text { Natural and } \\
\text { Anthropogenic } \\
\text { forcings }\end{array}$ & Emanuel & $\begin{array}{c}\text { SST_ANOM_IPSL_CM5A_RCP4.5 } \\
+ \\
\text { SST_AMIP_CLIM }\end{array}$ \\
\hline HIST1_GHG & $\begin{array}{c}\text { Historical } \\
(1950-2000) \\
\text { Decadal time } \\
\text { slice runs for } \\
(1951-1960), \\
(1961-1970), \\
(1971-1980), \\
(1981-1990), \\
(1991-2000)\end{array}$ & $\begin{array}{l}\text { Natural and } \\
\text { GHG-only } \\
\text { forcings. Land } \\
\text { use and aerosol } \\
\text { fields are set to } \\
1886 \text { values }\end{array}$ & Emanuel & $\begin{array}{c}\text { SST_ANOM_IPSL_CM5A_HIST_GHG } \\
+ \\
\text { SST_AMIP_CLIM }\end{array}$ \\
\hline HIST1_PIGHG & $\begin{array}{c}\text { Historical: } \\
\text { Decadal time } \\
\text { slice runs for } \\
(1951-1960), \\
(1961-1970), \\
(1971-1980), \\
(1981-1990), \\
(1991-2000)\end{array}$ & $\begin{array}{l}\text { Includes Natural } \\
\text { variations, } \\
\text { Aerosol forcing } \\
\text { and Land-use } \\
\text { change. The } \\
\text { concentration of } \\
\text { GHGs are set to } \\
1886\end{array}$ & Emanuel & $\begin{array}{c}\text { SST_ANOM_IPSL_CM5A_HIST } \\
+ \\
\text { SST_AMIP_CLIM }\end{array}$ \\
\hline
\end{tabular}


Table.3. List of 21 CMIP5 models used in this study, their sponsor, country and name.

\begin{tabular}{|c|c|}
\hline Sponsor and Country & Model name \\
\hline Beijing Climate Centre Climate System Model, China & BCC-CSM1-1 \\
\hline $\begin{array}{l}\text { Meteo-France / Centre National de Recherches Meteorologiques, } \\
\text { France }\end{array}$ & CNRM-CM5 \\
\hline Centro Euro-Mediterraneo sui Cambiamenti Climatici, Italy & CMCC-CM \\
\hline $\begin{array}{l}\text { Commonwealth Scientific and Industrial Research Organisation } \\
\text { (CSIRO), Australia }\end{array}$ & CSIRO-Mk3-6-0 \\
\hline \multirow{3}{*}{$\begin{array}{l}\text { Geophysical Fluid Dynamics Laboratory, National Oceanic and } \\
\text { Atmospheric Administration (NOAA), USA }\end{array}$} & GFDL-CM3 \\
\hline & GFDL-ESM2M \\
\hline & GFDL-ESM2G \\
\hline \multirow{3}{*}{$\begin{array}{l}\text { National Aeronautics and Space Administration (NASA) / Goddard } \\
\text { Institute for Space Studies (GISS), USA }\end{array}$} & GISS-E2H \\
\hline & GISS-E2-R \\
\hline & GISS-E2_R-CC \\
\hline \multirow[t]{4}{*}{ Met Office Hadley Centre, UK } & HadGEM2-AO \\
\hline & HadCM3 \\
\hline & HadGEM2-ES \\
\hline & HadGEM2 CC \\
\hline Institute for Numerical Mathematics, Russia & INMCM4 \\
\hline \multirow[t]{2}{*}{ Institute Pierre Simon Laplace, France } & IPSL-CM5A-MR \\
\hline & IPSL-CM5A-LR \\
\hline \multirow{3}{*}{$\begin{array}{l}\text { Centre for Climate System Research (University of Tokyo), National } \\
\text { Institute for Environmental Studies and Frontier Research Center for } \\
\text { Global Change (JAMSTEC), Japan }\end{array}$} & MIROC-ESM-CHEM \\
\hline & MIROC5 \\
\hline & MIROC-ESM \\
\hline Meteorological Research Institute, Japan & MRI-CGCM3 \\
\hline
\end{tabular}


Table.4. Summary of trends in the frequency of heavy precipitation events over Central India, with intensities $\geq 100 \mathrm{~mm} \mathrm{day}^{-1}$, from IMD observations and LMDZ4 simulations

\begin{tabular}{|c|c|c|c|c|}
\hline & $\begin{array}{c}\text { Trend in the } \\
\text { frequency count }\end{array}$ & $\begin{array}{c}\text { Mean frequency } \\
\text { count }\end{array}$ & $\begin{array}{l}\text { \% change w.r.t } \\
\text { mean frequency } \\
\text { count }\end{array}$ & $\begin{array}{c}\text { P value based } \\
\text { on the two } \\
\text { tailed student's } \\
\text { t-test }\end{array}$ \\
\hline $\begin{array}{l}\text { IMD dataset } \\
(1951-2005)\end{array}$ & $\begin{array}{l}430 \text { units } \\
(55 \text { years })^{-1}\end{array}$ & 1448 & $30 \%$ & $\mathrm{P}<0.01$ \\
\hline $\begin{array}{c}\text { HIST1 } \\
(1951-2005)\end{array}$ & $\begin{array}{l}499 \text { units } \\
(55 \text { years })^{-1}\end{array}$ & 1652 & $30 \%$ & $\mathrm{P}<0.01$ \\
\hline $\begin{array}{c}\text { HIST2 } \\
(1951-2005)\end{array}$ & $\begin{array}{l}638 \text { units } \\
(55 \text { years })^{-1}\end{array}$ & 1507 & $42 \%$ & $\mathrm{P}<0.01$ \\
\hline $\begin{array}{l}\text { HISTNAT1 } \\
(1951-2005)\end{array}$ & $\begin{array}{l}-34 \text { units } \\
(55 \text { years })^{-1}\end{array}$ & 1356 & $-3 \%$ & $\begin{array}{l}\mathrm{P}=0.2(\mathrm{not} \\
\text { significant })\end{array}$ \\
\hline $\begin{array}{l}\text { HISTNAT2 } \\
(1951-2005)\end{array}$ & $\begin{array}{c}+6 \text { units } \\
(55 \text { years })^{-1}\end{array}$ & 1233 & $0.5 \%$ & $\begin{array}{l}\mathrm{P}=0.8 \text { (not } \\
\text { significant) }\end{array}$ \\
\hline $\begin{array}{c}\text { RCP4.5 } \\
\text { (2006-2095) }\end{array}$ & $\begin{array}{l}750 \text { units } \\
(90 \text { years })^{-1}\end{array}$ & 1976 & $38 \%$ & $\mathrm{P}<0.01$ \\
\hline
\end{tabular}


Table.5: Comparison of JJAS mean and standard deviation of rainfall and $850 \mathrm{hPa}$ zonal winds between observations (GPCP / NCEP reanalysis) and models (LMDZ4, IPSL-CM5A-MR, IPSLCM5A-LR). Rainfall averages are shown both for the Western Ghats $\left(72^{\circ}-76^{\circ} \mathrm{E}, 10^{\circ}-19^{\circ} \mathrm{N}\right)$ and the Indian $\left(70^{\circ}-90^{\circ} \mathrm{E}, 10^{\circ}-28^{\circ} \mathrm{N}\right)$ land regions. The $850 \mathrm{hPa}$ zonal winds are averaged over a broader region $\left(5^{\circ} \mathrm{N}-22^{\circ} \mathrm{N}, 55^{\circ} \mathrm{E}-90^{\circ} \mathrm{E}\right)$ over India and the adjoining Arabian Sea and Bay of Bengal.

\begin{tabular}{|c|c|c|c|c|}
\hline & $\begin{array}{l}\text { GPCP rainfall / } \\
\text { NCEP winds }\end{array}$ & LMDZ4 & IPSL-CM5A-MR & IPSL-CM5A-LR \\
\hline $\begin{array}{l}\text { Mean \& (std. dev) of } \\
\text { rainfall over the } \\
\text { Western Ghats }\end{array}$ & $\begin{array}{l}10.3 \mathrm{~mm} \mathrm{day}^{-1} \\
\left(1.6 \mathrm{~mm} \mathrm{day}^{-1}\right)\end{array}$ & $\begin{array}{l}10.8 \mathrm{~mm} \mathrm{day}^{-1} \\
\left(3.3 \mathrm{~mm} \mathrm{day}^{-1}\right)\end{array}$ & $\begin{array}{l}5.4 \mathrm{~mm} \mathrm{day}^{-1} \\
\left(1.6 \mathrm{~mm} \mathrm{day}^{-1}\right)\end{array}$ & $\begin{array}{l}3.8 \mathrm{~mm} \mathrm{day}^{-1} \\
\left(1.1 \mathrm{~mm} \mathrm{day}^{-1}\right)\end{array}$ \\
\hline $\begin{array}{l}\text { Mean \& (std. dev) of } \\
\text { rainfall over the Indian } \\
\text { land region }\end{array}$ & $\begin{array}{l}7.6 \mathrm{~mm} \mathrm{day}^{-1} \\
\left(0.8 \mathrm{~mm} \mathrm{day}^{-1}\right)\end{array}$ & $\begin{array}{c}6.5 \mathrm{~mm} \text { day }^{-1} \\
\left(1.5 \mathrm{~mm} \mathrm{day}^{-1}\right)\end{array}$ & $\begin{array}{l}4.3 \mathrm{~mm} \mathrm{day}^{-1} \\
\left(0.8 \mathrm{~mm} \mathrm{day}^{-1}\right)\end{array}$ & $\begin{array}{l}4.5 \mathrm{~mm} \mathrm{day}^{-1} \\
\left(0.7 \mathrm{~mm} \mathrm{day}^{-1}\right)\end{array}$ \\
\hline $\begin{array}{l}\text { Mean \& (std. dev) of } \\
\text { zonal wind }\end{array}$ & $\begin{array}{l}9.3 \mathrm{~ms}^{-1} \\
\left(0.6 \mathrm{~ms}^{-1}\right)\end{array}$ & $\begin{array}{c}9 \mathrm{~ms}^{-1} \\
\left(0.8 \mathrm{~ms}^{-1}\right)\end{array}$ & $\begin{array}{l}7.3 \mathrm{~ms}^{-1} \\
\left(0.4 \mathrm{~ms}^{-1}\right)\end{array}$ & $\begin{array}{l}6.1 \mathrm{~ms}^{-1} \\
\left(0.3 \mathrm{~ms}^{-1}\right)\end{array}$ \\
\hline
\end{tabular}

